\title{
ADVANCED DIRECT LIQUERACTION CONCEPTS fOr PETC GENERIC UNITS
}

\author{
Quartexly Technical Progress Report \\ for Period January 1992 through March 1992
}

\author{
by \\ University of Kentucky \\ Center for Applied Energy Research
}

Sandia National Laboratories

Consolidation Coal Company

IDP Associates

April 1992

Prepared for

The U. S. Department of Energy

Under Contract No.

DE-AC22-91PC91040

\section{DISCLAIMER}

This reprort was prepared as an account of work sponsored by an agency of the United States Government. Neither the United States Government nor any agency thereof, nor any of their employees, makes any wartanty, express or implied, or assumes any legul liability or responsibility for the accuracy, completentss, or usefulness of any information, apparatus, product, or process disclosed, or represents that its use would not infringe privately owned rights. Reference herein to any specific commercial product, process, or service by trade name, trademark, manufacturer, or otherwise does not necessarily constitute or imply its endorsement, recom. mendation, or favoring by the United States Government or any' agency thereof. The views and opinions of authors expressed herein do not necessarily state or reflect those of the Unitod States Government ot any agency therosf. 
SUMMARY

Task 1.2 - Laboratory Support

Task 2.1 pretreatment Work

Task 2.3 Catalyst Studies

WORK PEREORMED

Task 1.2 - Laboratory Support (CONSOL) A

Task 2.1.1 pretreatment work at CAER

Literature Review on High Temperature

water Treatment of Coal

1. Introduction

2. Background

2.1. Role of Water

2.2 The Effect of High Temperature pretreatment on Coal processing 9

2.3 Chemistry of Hydrothermal pretreatment 13

2.4 Liquefaction with supercritical water 15

a. Effect of Coal Rank. 15

b. The Water-Gas Shift Reaction and pH Dependence on Liquefaction 15

c. Product Distribution and Composition 16

d. Removal of Heteroatoms

2.5 Kinetics and Mechanism of Coal Conversion

in $\mathrm{CO} / \mathrm{H}_{2} \mathrm{O}$ Systems
2.6 Cross-linking Reactions and Impact.

of oxygen Functional Groups

in the coal structure

2.7 Chemical Pretreatment of coal 20

3. Summary

4. Experimental plan for screening Operatinc:

22

Variables 23

4.1 Coal and Coal preparation 23

4.2 Pretreatment Catalyst 24

4.3 Reactor Capacity: Micro-Reactors and
Stirred Autoclaves

4.4 Temperature 24

4.5 Reducing gas 24

4.6 Water Concentration and Co-solvent 24

4.7 Pretreatment Time 25

4.8 Organic Solvent Used in First Stage 25

4.9 Product Handling 25

4.10 Product Characterization and Analysis 26

4.11 Optical Light Microscopy 26

TASK 2.3.1 Iron-Based, Dispersed Hydroliquefaction 26

Experimental Methods 27

Product Work-Up 27

Reagents Used 29

Experimental Error $\quad 30$

Results and Discussion 31 


$\begin{array}{cr}F_{3} \mathrm{C} & 31 \\ \text { Fe, } & 32 \\ \text { Moly Naphthenate and Iron Naphthenate } & 32 \\ \text { THF Conversion } & 33 \\ \text { TASK 2.3.3 Catalyst Studies at Sandia } & 38 \\ \text { Background } & 38 \\ \text { Catalyst Studies } & 39 \\ \text { Solvent Pretreatment } & 40 \\ \text { Platinum Catalyst Results } & 41 \\ \text { Cobalt Molybdenum Catalyst Results } & 41 \\ \text { Conclusions } & 42 \\ \text { Future Tests } & 42 \\ \text { Laboratory Support } & 43 \\ \text { REFERENCES } & \end{array}$

\section{IIST OF TABIES}

Table

page

1

2

3

Eigure

paqe

1

2

3

4

\section{Title}

Data From First Stage Liquefaction Experiments

37

Pt HTO catalyst (Total system Pressure=1400 psig)

41

Como catalyst (Total system Pressure $=1000$ psig)

42

\section{IIST OF FIGURES}

\section{Title}

Mechanism for Coal Liquefaction in $\mathrm{CO} / \mathrm{H}_{2} \mathrm{O}$

Wyodak Liquefaction with $\mathrm{Fe}_{3} \mathrm{C}$

Wyodak Liquefaction with $\mathrm{Fe}_{7} \mathrm{C}_{3}$ and Sulfur 


\section{SUMMARY}

Task 1.2 - Laboratory Support (CONSOL)

Contract work was limited this quarter to those activities which received pre-NEPA approval. Samples of Black Thunder coal (pulverized and un-ground), heavy distillate (V-1074), de-ashed resid $(V-130)$ and ashy resid (V-1082) from Wilsonville Run 262 and respective analyses and MSDS sheets for these materials were received. The process (recycle) solvent blend used at wilsonville consisted of $42.7 \%$ distillate, $6.6 \%$ de-ashed resid, and 50.78 ashy resid by weight.

The heavy distillate (V-1.074) sample from wilsonvilie Run 262 was warmed to $\sim 100^{\circ} \mathrm{C}$, mixed, and divided into aliquots for distribution to the University of Kentucky and Sandia. The remainder $(16 \mathrm{~kg}$, $\sim 36 \mathrm{jb}$ ) was saved for later use. Although a tar-like solid at room temperature, this material readily melts and, at $100^{\circ} \mathrm{C}$, has a viscosity similar to watex.

The deashed $(\mathrm{V}-120)$ and ashy $(\mathrm{V}-1082)$ resid samples wert ground in a hammer mill to approximately $-1 / 4^{\prime \prime}$ and weighed. The $54.9 \mathrm{~kg}$ of ashy resid obtained from wilsonville is insufficient for supplying the anticipated need for this sample.

Triple-layer (polyethylene, aluminum and Tyvek) bags and a Tefloncoated heat sealing unit were purchased and used to package all solid samples. Ground samples are first placed in appropriately sized Zip-Loc bags, then purged with $\mathrm{N}_{2}$ via a lance inserted into one side of the bag, evacuated and then sealed. The sealed zip-Joc bag then is placed inside a triple-layer bag. The triple-layer bag then is purged with $\mathrm{N}_{2}$, evacuated and heat sealed. This will be the standard method for storage of solid samples under this 
contract. Samples were shipped to the participants.

\section{Task 2.I Pretreatment Work}

A literature review and analysis of the effect of high temperatule water pretreatment on coal was completed during this reporting period. This review includes the most recent publications in this area and analyzes the results that have been obtained on a wide range of coals under a variety of conditions using both single and multi-phase neat aqueous systems in addition to the effects of alkaline solutions and carbon monoxide atmospheres on these reactions. Appended to the review is a list of over 60 references, which, though extensive, does not include all of the references that were found that relate to this area. For example, the extensive information on supercritical processing of coal has not been reviewed in this study. From the information gleaned from this review a detailed work outline for CAER was prepared. Work is currently progressing on this plan and results will be provided as they become available.

\section{Task 2.3 Catalyst studies}

Studies on iron-based, dispersed hydroliquefaction catalysts have focused on ultra-fine particle (UFP) iron carbides. Both the $\mathrm{F}_{3} \mathrm{C}$ and $\mathrm{Fe}_{7} \mathrm{C}_{3}$ phases, which were produced by laser pyrolysis at CAER were tested as coal liquefaction catalyst precursors in 15-minute, vertically-shaken microautoclave experiments. The data suggests little activity for the $\mathrm{Ee}_{3} \mathrm{C}$ phase, as produced, whether alone or with added sulfur, and moderate activity for the Fe, $\mathrm{C}_{3}$ phase. Comparison experiments with molybdenum and iron naphthenate gave results similar to the latter phase at mid-range liquefaction temperatures, although the effectiveness of the dispersed molybdenum compound was much better at higher temperature $\left(440^{\circ} \mathrm{C}\right)$. 
Two different types of supported catalysts were used to test activity for the combined water-gas shift hydrogenation of a synthetic donor solvent. The first catalyst was a hydrous titanium oxide (HTO) catalyst which had been exchanged with platinum, and the second was an alumina catalyst loaded with cobalt and molybdenum.

The platinum catalyst was synthesized as a candidate catalyst to increase the rate of the solvent hydrogenation reaction. This catalyst gave a $95 \%$ conversion for $\mathrm{CO}$ (equilibrium conversion is $97 \%$ ) in the water-gas shift reaction at $275^{\circ} \mathrm{C}$ after it was calcined at $500^{\circ} \mathrm{C}$. Solvent hydrogenation using this catalyst was lower than that of previous catalyst tests (Pyxene hydrogenation was 698 for a NiMO HTO, and $58 \%$ for the Pt HTO at $275^{\circ} \mathrm{C}$ ). However, the platinum catalyst performed well at $300^{\circ} \mathrm{C}$, hydrogenating 80 of the pyrene in the feed.

The cobalt molybderium catalyst also showed lower hydrogenation activity $\left(34 \%\right.$ pyrene hydrogenated at $\left.275^{\circ} \mathrm{C}\right)$. Conversion of $\mathrm{CO}$ was lower $\left(60 \%\right.$ at $\left.275^{\circ} \mathrm{C}\right)$ with the cobalt molybdenum catalyst, possibly due to the lack of an alkalj promoter.

These results show that the best catalysts tested to date, for the combined water-gas shift solvent hydrogenation, is a sulfided NiMo catalyst (See Oct-Dec 1991 Quarterly Report). 
WORK PERFORMED

\section{TASK 1.2 - IAABORATORY SUPPORT (CONSOL)}

Contract work was limited this quarter to those activities which received pre-NEPA approval.

Samples of Black Thunder coal (pulverized and un-ground), heavy distillate (V-1074), de-ashed resid (V-130) and ashy resid (V-1082) from Wilsonville Run 262 and respective analyses and MSDS sheets for these materials were received. Wilsonville personnel also provided the blend ratio of process solvent components for operations on september 16, 1991, the date our oil samples were obtained. The process (recycle) solvent blend used at wilsonville consisted of $42.7 \%$ distillate, 6.6\% de-ashed resid, and $50.7 \%$ ashy resid by weight. Some additional information will be obtained about operation on this date, which was between material balance periods $D$ and $E$ of Run 262. The requirements of Sandia National Laboratory and the University of Kentucky Center for Applied Energy Research (UK/CAER) for these materials were obtained.

The heavy distillate (V-1074) sample from Wilsonville Run 26? was warmed to $\sim 100^{\circ} \mathrm{C}$, mixed, and divided into aliquots for distribution to the University of Kentucky $(24 \mathrm{~kg}, \sim 52 \mathrm{lb})$ and Sandia ( $3 \mathrm{~kg}, \sim 6$ 1b). The remainder $(16 \mathrm{~kg}, \sim 36 \mathrm{lb})$ was saved for later use. Although a tar-like solid at room temperature, this material readily melts and, at $100^{\circ} \mathrm{C}$, has a viscosity similar to water.

The deashed $(V-120)$ arid ashy $(V-1.082)$ resid samples were ground in a hammer mill to approximately $-1 / 4^{\prime \prime}$ and weighed. The $54.9 \mathrm{~kg}$ ( $120.8 \mathrm{lb})$ of ashy resid obtained from wilsonville is insufficient for supplying the requested samples $\left(\begin{array}{lll}133 & \mathrm{lb}\end{array}\right)$. UK/CAER agreed to work with less sample than originally requested, $47 \mathrm{~kg}$ (103 1b) vs $52.9 \mathrm{~kb}(.117 \mathrm{lb})$. 
Triple-layer (polyethylene, aluminum and Tyvek) bags and a Tefloncoated heat sealing unit were purchased. A clamco Model 254 heat sealer was installed, tested for sealing sample bags and used to package all solid samples. Ground samples are first piaced in appropriately sized $\mathrm{Zip-Loc}$ bags, then purged with $\mathrm{N}_{2}$ via a lance inserted into one side of the bag, evacuated and then sealed. The sealed zip-Loc bag then is placed inside a triple-layer bag. The triple-layer bag then is purged with $\mathrm{N}_{2}$, evacuated and heat sealed with the clamco sealer. This will be the standard method for storage of solid samples under this contract.

Samples were shipped to the participants in the quantities shown below.

\section{Material}

V-1074 Heavy Distillate

$\mathrm{V}-130$ De-Ashed Resid

V-1082 Ashy Resid

Black Thunder Coal (Ground)

\begin{tabular}{cc} 
wt $z$, Ib \\
\hline UK/CAER & Sandia \\
\hline 54.0 & 5.6 \\
8.6 & 1.0 \\
103.0 & 1.0 \\
16.0 & 1.0
\end{tabular}

A database was created for the materials to be obtained and generated under this project. This dBase $B$ database can be easily modified to accommodate any changes that may occur later in the program.

C. Izquierdo, E. Klunder and M. Baird of PETC visited CONSOL on Eebruary 25, 1992, to discuss the project status and objectives.

Task 2.1.1 Pretreatment Work at CAER

A literature review and analysis of the effect of high-temperature 
water pretreatment on coal was completed during this reporting period. This review includes the most recent publications in this area and analyzes the results that have been obtained on a wide range of coals under a variety of conditions using both single and multi-phase neat aqueous systems in addition to the effects of: alkaline solutions und carbon monoxide atmospheres on these reactions. Appended to the review is a list of over 60 references, which, though extensive, does not include all of the references that were found that relate to this area. For example, the extensive information on supercritical processing of coal has not been reviewed in this study. From the information gleaned from this review a detailed work outline was prepared and is included at the end of this section. Work is currently progressing on this work plan and results will be provided as they become available.

\section{Literature Review on High Temperature Watex Treatment of Coal}

\section{Introduction}

The current concept of coal liquefaction favors a series of integrated stages in which coal dissolution is optimized and the ensuing product slate is upgraded at mild reaction conditions. This line of approach followed from the recognition that high pressure and thermal processes (in excess of $450^{\circ} \mathrm{C}$ ) did not exclusively lead to desirable results. High reaction temperatures also favors thermolysis and hydrogenolysis over hydrogenation giving rise to higher distillate yjeld but also more refractory resids and hydrocarbon gas mix. Thus, the immediate incentives for a mild reaction process are:

(1) reduction of hydrocarbon gas make resulting in lower feed gas consumption and enhancement of hydrogen utilization efficiency;

(2) suppression of retrogressive reactions in primary coal. dissolution products leading to better product quality in 
distillates and resid material;

(3) production of high boiling residual products which are less refractory and more amenable to catalytic upgrading in a conventional second-stage hydrocracker;

(A) realization of significant cost saving associated with less expensive construction material and overall plant processing and operation.

A common approach toward achieving these goals involves the pretreatment of coal prior to the first stage of a multi-stage liquefaction scheme. The pretreatment methodulogy can vary from physico-chemical treatment of coal through demineralization, acidwashing $^{1}$ and solvent swelling, ${ }^{2}$ to pretreatment associated with a chemical process, such as in alkylation of coal and dissolution of coal with strong acids and bases.3,4,5

In the Advance Coal Liquefaction Concept Proposal (ACLCP) carbon monoxide (CO) and water have been proposed as the primary reagents in the pretreatment process. The main objective of this project is to develop a methodology for pretreating coal under mild conditions based on a combination of existing processes which have shown great promise in liquefaction, extraction and pyrolysis studies. The aim of this pretreatment process is to partially depolymerise the cual, eliminate oxygen and diminish the propensity for retograde reactions during subsequent liquefaction. The desirable outcome of the co pretreatment step should be:

(1) enhanced liquefaction activity and/or selectivity toward products of higher quality due to chemical modification of the coal structure;

(2) cleaner downstream products; 
An overview of some of the relevant work in the literature is documented in this report together with a proposal of work to be carried out at the Center for Applied Energy Research, University of Kentucky, in the ACLCP program.

\section{Background}

\subsection{Role of Water}

The role of water in liquefaction, extraction and pyrolysis studies with coal and model compounds have been well documented.1,6,7 In liquefaction, water in combination with carbon monoxide has been shown to be an efficient hydrogen donor. Water also serves as a medium in which:

(1) coal material can be slurried and transported to reaction zones,

(2) water soluble catalysts can be dispersed, and

(3) reactive fragments can partake in various organic and ionic reactions.

In recent years there has been a sharp focus on the supercritical properties of water to enhance the performance of coal under a variety of process conditions.8.9 Water becomes supercritcal at $374^{\circ} \mathrm{C}$. At 220 bar the density of both the gas and liquid is 0.32 grams per $\mathrm{CC}$. Under these conditions, water is a highly compressed fluid. In supercritical extraction, the supercritical densities are much larger than typical gas densities, therefore the fluid acts as a strong solvent for the condensed phase when brought into contact with a relatively non-volatile solid or liquid. Further it was thought that the supercritical fluid would also serve to solvate reactive components, thus reducing condensation reactions 
and charring.

water may also participate as a reactant in the thermolytic chemistry of certain model compounds. In the presence of water, dibenzyl ether decomposes at $374^{\circ} \mathrm{C}$ by both a pyrolytic and hydrolytic pathway. ${ }^{10}$ The removal of nitrogen from heterocyclic compounds, such as isoquinoline, is accelerated in the presence of supercritical water (SCW). ${ }^{11}$ Most recently, it was suggested that in the presence of SCW the hydrolysis of coal model compounds proced hrough a transition state that is more polar than the reactants. ${ }^{12}$

\subsection{The Effect of High Temperature pretreatment on Coal} Processing

Much of the work reported in the literature on steam/scw pretreatment of coal pertained mainly to pyrolysis and extraction studies. Very few were directed toward liquefaction even though there is some parallel between these reactions, particularly when $\mathrm{CO}$ and $\mathrm{H}_{2} \mathrm{O}$ are being utilized (see section 2.5).

The effect of using SCW on the extraction of coal and related substances have been demonstrated by Modell and co-workers. ${ }^{13}$ They reacted glucose, cellulose, maple sawdust, and coal with water at its SC temperature and pressure. Although char was the chief product when these substances were pyrolysed, no char was found at these conditions in runs with glucose, cellulose and maple sawdust. The presence of SCW appears to prevent the formation of condensation products by keeping the reactive intermediates in a highly solvated and dispersed state.

These findings were further reinforced by Deshpande et al. ${ }^{14}$ who developed an experimental apparatus for injecting coal into an autoclave containing preheated supercritical water. They reacted German brown coal, lignite and bituminous coal and glucose at both 
subcritical and supercritcal water (SCW) densities. A significantly larger quantity of THE-insoluble char was reported when operating at subcritical densities and when the coal was mixed with water before heating to supercritical conditions. They concluded that by injecting ambient coal into SCW, the coal is heated up rapidly such that the reactive intermediates are extracted before retrogressive reactions can occur. Appasently the water must be near its Eritical density for this process to work well. They also reported a high percentage of ash is being leached out of the coal during the extraction process.

Supercritical water distillation has also been combined in a single step with aqueous liquefaction to separate the oil and asphaltene from the coal char. ${ }^{\text {is }}$ Barton showed that the liquids from coal hydrogenation can be transported away from the insoluble char waterial by SCW.

Swanson et al. ${ }^{16}$ extracted coal in a semi-continuous reastor system and reported that coal conversions and extract yields increased with operating temperature and pressure. At $380^{\circ} \mathrm{C}$ col conversion and extract yield of up to 50 and 30 wt. $\frac{}{5}$, respectively, was obtained. The conversions also increased with decreasing coal rank and correlated well with the percent volatile matter in the coal. They showed that scW in combination with $\mathrm{CO}$ is capable of extracting the low molecular weight and hydrogen-rich component of the coal while leaving behind a highly carbonaceous residue.

In a steam pyrolysis experiment performed at $740^{\circ} \mathrm{C}$, Graff and Brandes reported a two fold increase in liquid yields and a 208 increase in total volatile yields when Illinojs No.6 coal was pretreated with subcritical steam at 50 atmosphere pressure between the temperature range $320-360^{\circ} \mathrm{C}$. This effect was not observed when the coal was in contact with an inert gas at the same pressure and temperatures. At higher temperatures $\left(>360^{\circ} \mathrm{C}\right)$ the benefits of pretreatment were lost. The temperature regime at which the coal 
responds beneficially to the pretreatment process appeared to be unique to each individual coal used in the experiment." Further, work using ${ }^{13} \mathrm{C}$ NMR and ETIR spectral analysis have indicated that different coal may respond differently to the hydrothermal pretreatment process. ${ }^{18}$ In the cases where steam pretreatment had worked, Brandes and Graffi,17 observed a morphological change (increased hydrophilicity, agglomeration) in the coal structure in addition to chemical modifications. Chemical analyses determined that the pretreated coal had lower oxygen content and exhibited reduced hydrogen bonding and increased hydrophilicity compared to untreated coal. Using a "C ortho-alklylation technique, they were able to establish that steam treated coal contained twice as many hydroxyl groups as the raw coal. From this observation, they postulated that the steam reacted with the ether linkages in the coal, forming hydroxyl groups and, in the process, removing substantial covalent cross-linking in the coal structure.

Recently, Khan et al. ${ }^{19}$ showed that steam treatment for a low-rank coal resulted in significant reduction in total oxygen concentration while for high rank coals oxygen concentration was either unchanged or increased. The reduction in the low-rank coal came from reductions in the methoxy, phenolic, and aliphatic carboryl and carboxyl groups in the coal. Phenols were the major component found in the pretreatment water after the reaction. Contrary to Graff and Brandes's results' they reported that the volatile yields in vacuum pyrolysis did not increase as a result of steam pretreatment for the five coals that they investigated. However, they acknowledged that this conclusion was based primarily on only one of the Eive coals which had not been exposed to air after the treatment process.

- Brandes and Graff (see Ref. 1) have shown that the beneficial effect of steam treatment is lost when the pretreated samples are exposed to air. 
Ross and Hirschon ${ }^{20}$ hydrothermally treated Illinois No.6 coal at $250^{\circ} \mathrm{C}$ ( $38 \mathrm{~atm}$ ) for 30 minutes followed by pyrolysis of the pretreated sample in a field ionization mass spectrometer (EIMS) chamber from $100-500^{\circ} \mathrm{C}$. They found that the total volatile yield for the pretreated coal was virtually identival with that of the raw coal, viz., $23 \%$ and $22 \%$ for the treated sample and as-received coal, respectively. However, the differences in product make-up were significant. The pretreated sample showed a broad increase in lower molecular weight material at the expense of higher molecular weight tars as compared to the raw coal. Their data also showed that the evolution of the low molecular weight material (alkylbenzenes, alkylphenanthrenes, anthracenes, alkylpyrenes and naphthalenes) from the organic matrix occurred at a considerably lower temperature after the hydrothermal pretreatrient. These results led them to conclude that the pretreatment led not only to the release of the low molecular weight material and trapped material but also to changes in the coal structure such that the tar precursors generate additional lower weight material upon thermolysis. Though the mechanism remains unclear recent work by Hoering ${ }^{21}$ underscores the impact of hydrothermal treatment on the generation of petroleum products, including long chain normal alkanes, aromatics and biomarkers from Messel shale which have been pre-extracted. When $\mathrm{D}_{2} \mathrm{O}$ was used, deuterium was heavily incorporated into the hydrocarbons.

In addition, Ross and Hischon ${ }^{20}$ also reported that the bulk sulfur content of the coal was reduced by about $60 \%$ during pretreatment with steam. This level of reduction was matched by the lowered ash levels. Similar findings were reported by Rozgonyi et al."2 who reported $39 \%$ and $31 \%$ reductions, respectively, in total sulphur and ash for a bituminous coal after hydrothermal treatment at $292^{\circ} \mathrm{C}$ for 40 minutes.

Mixtures of tetrahydroquinoline(THQ), quinoline, or tetralin(1020ㄱ) with supercritical water (SCW) have beer used to liquefy 
Powhatan and Bruceton coal at $380^{\circ} \mathrm{C}$ and $30 \mathrm{MPa} .^{3}$ THF soluble yields of up to $74 \%$ were obtained with the SCW-THQ mixtures. In all instances, the THF soluble yields were dependent on the concentration of solvent in the misture.

\subsection{The Chemistry of Hydrothermal Pretreatment}

The chemistry of hydrothermal pratreatment and how it affects the conversion of coal during processing is not well understood. One of the possible mechanisms by which steam induces change is that morphological changes to the coal structure affect ultimate mass transfer rates because water reacts to increase pore volume by opening the coal structure for subsequent reactions thereby improving conversion. ${ }^{23}$ Brandes et al. ${ }^{18}$ have reported a two-fold increase in the sweiling ratio of steam treated coal over that of raw coal. However, such factors are not clear cut since steam pretreatment has also been noted to cause agglomeration. 1" serio et al., ${ }^{24}$ have reported that the beneficial effect of steam pretreatment was negated and the liquefaction yields reduced when the reactor containing the steam treated coal was not shaken. They contend that as a result of agglomeration the coal was more difficult to liquefy and, presumably in this case, mass transport became a limiting factor in the conversion process.

It has been noted in many studies that hydrothermal treatment has generally a greater impact on low-rank coals (high o/C ratio) than high-rank coals.18,19 The beneficial effect of hydrothermal pretreatment must involve a balance between bond breaking and cross-linking reactions. On one hand, the partial remcval of covalent cross-links by steam results in removal of ether type linkages as reported by Graff and Brandes."11 On the other, fhenolic groups are evolved which subsequently may undergo selfcoupling reactions. Studies have shown that various phenolic compounds can undergo rapid coupling reactions when $\mathrm{H}$-donor solvents are absent. Trewhella et al. have reported that the 
polymerization of phenolic compounds to larger ring furans is significantly reduced in the presence of hydrogen donors such as tetralin.

Recently, Tse et al. ${ }^{23}$ studied the coupling reactions of catechol in the presence of the mineral kaolinite (a common clay mineral found in coals) and showed how these reactions can be modified by kaolin and water in the range from $300-400^{\circ} \mathrm{C}$. Catechol underwent very little condensation at $400^{\circ} \mathrm{C}\left(75 \%\right.$ unreacted); at $350^{\circ} \mathrm{C} 92 \%$ was unreacted. However, the presence of kaolin significantly accelerated the reactior. For example, aftex three hours at $350^{\circ} \mathrm{C}$ a mixture of catechol and kaolin was found to contain only $46 \%$ unreacted catechol compared to $92 \%$ when kaolin was not present. Addition of water to the kaolin-catechol mixture inhibited the coupling reaction with recovery of $89 \%$ of unreacted catechol. similar results were reported for reactions carried out at $400^{\circ} \mathrm{C}$. These results suggest that under pretreatment conditions in the presence of water crosslinking due to coupling reactions by phenolic groups should be significantly reduced leading to larger yields and/or better quality products. ${ }^{23}$

Bienkowski et al. ${ }^{9}$ identified dihydroxyl aromatics in their toluene solubles after they pretreated coal with steam at $200^{\circ} \mathrm{C}$ followed by extraction with $\mathrm{SC}$ steam at $400^{\circ} \mathrm{C}$. This is unexpected since polyhydroxy aromatics, which are a basic unit in lignin structures and are presumed to persist in low-rank coal structures, are not found to be substantial constituents in coal liquefaction products (see Reference 25). Conversely, significant amounts of these compounds have been identified in rapid pyrolysis studies. The survival of the dihydroxyl aromatics suggests that scw is able to stabilize and extract reactive fragments from coal before they can undergo retrogressive reactions.

Further, under hydrothermal conditions bond scission of organic moieties involving ionic pathways may take place. The ionic and 
thermal chemistry of various ethers and esters have been studied by Siskin et al." They showed that at low temperature $\left(250^{\circ} \mathrm{C}\right)$ ionic mechanisms provided a pathway for C-O bond cleavage while at higher temperatures, radical pathways were favored.

In $\mathrm{CO} / \mathrm{H}_{2} \mathrm{O}$ liquefaction, $\mathrm{Ross}^{28}$ proposed a hydride transfer mechanism involving phenol/ketol tautomers in the coal structure to provide a route to coal conversion without depending entirely on thermal bond scission.

\subsection{Liquefaction with Supercritical water}

Although the primary objective of this pretreatment project is not to liquefy the coal, a brief summary of the major findings in coal liquefaction using $\mathrm{CO} / \mathrm{H}_{2} \mathrm{O}$ provides a useful background for this project. Supercritcal and subcritical water in combination with a variety of reducing gases $\left(\mathrm{CO}, \mathrm{H}_{2} / \mathrm{CO}\right.$ and $\left.\mathrm{H}_{2} \mathrm{~S}\right)$ and catalysts have been shown to be an excellent source of hydrogen for the reduction of coal. Most of these studies were conducted at below the density of water at the critical conditions because of the additional pressure effect of the reducing gases. The following discussion summarizes the main findings from these studies.

\section{a. Effect of Coal Rank.}

Appell et al. ${ }^{29,30}$ and others ${ }^{31,32,33}$ have shown that coal liquefaction under $\mathrm{CO} / \mathrm{H}_{2} \mathrm{O}$ reaction conditions is dependent on coal rank. Coal conversion decreases as rank increases. With bituminous coal, lignite, peat, dry leaves and pine needles, Delert and siekmann ${ }^{32}$ found that conversion increased as the $\mathrm{H} / \mathrm{C}$ and $\mathrm{O} / \mathrm{C}$ ratios of the input material increased. They also found that the significance of the oxygen functional groups was greater in $\mathrm{CO} / \mathrm{H}_{2} \mathrm{O}$ than in $\mathrm{H}_{2}$ systems.

b. The Water-Gas Shift Reaction and $\mathrm{pH}$ Dependence on Liquefaction 
The addition of a metal hydroxide or carbonate such as $\mathrm{KOH}$ and $\mathrm{NaOH}$ has a significant effect on the conversion process. ${ }^{28-37.34}$ It has been pointed out that any hydroxide ion generator can catalyze the water-gas shift (WGS) reaction and, therefore, may be used to promote coal liquefaction in $\mathrm{CO} / \mathrm{H}_{2} \mathrm{O}$. Ross et al. ${ }^{35}$ calculated that

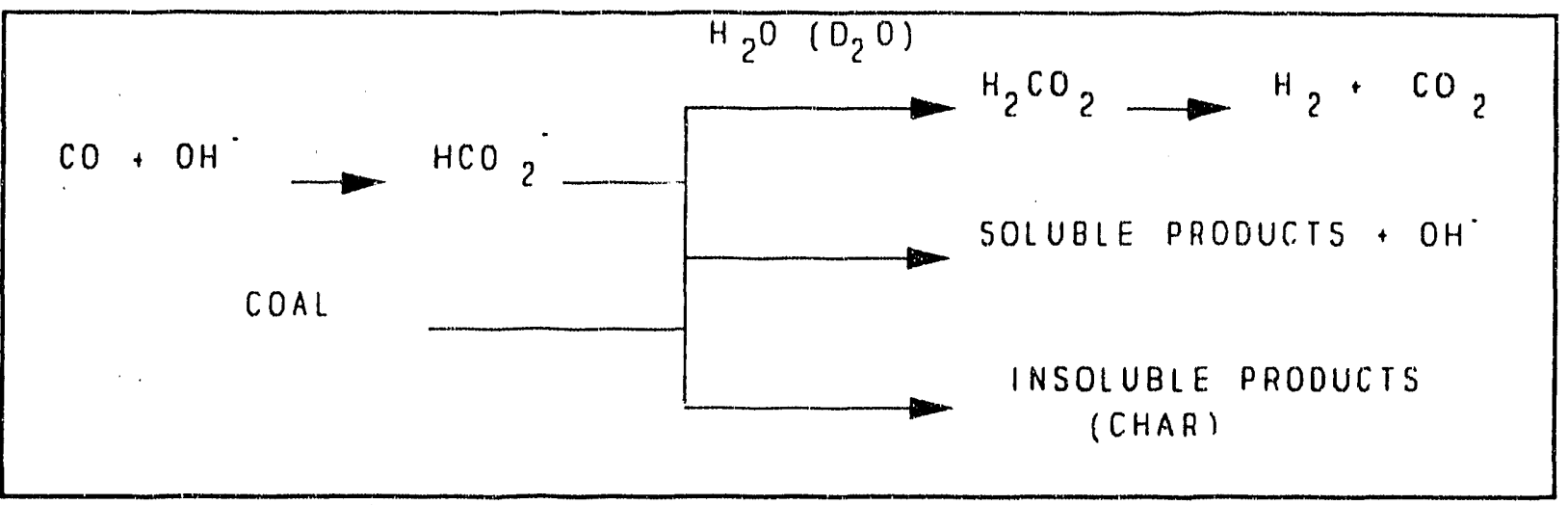

Figure 1 Mechanism for coal liquefaction in $\mathrm{CO}_{\mathrm{H}} \mathrm{O}$ (Ross, et al., Ref. 36)

the turnover number (i.e., the molar ratio of $\mathrm{H}$ added to the coal divided by the quantity of base) for the reaction of Illinois No.6, $(P S O C-26) \mathrm{coal}$ in $\mathrm{KOH}$ was 80-90. The addition of an organic solvent tended to slow down the WGS reaction but it did not necessarily lead to a decline in coal conversion. ${ }^{3.3}$ Ross et al. demonstrated that the initial $\mathrm{pH}$ of the water has a significant bearing on the conversion and the $\mathrm{pH}$ at which there is rapid conversion activity is dependent on the metal catalyst. ${ }^{35,36}$ The performance of the catalyst seems to be related to its high oxidation state.

\section{c. Product Distribution and Composition}

$\mathrm{Lim}^{37}$ showed that there is a significant increase in selectivity for methylene chloride/light petroleum soluble oil product when Australian brown coals were reacted with $\mathrm{CO} / \mathrm{H}_{2} \mathrm{O}$ in the presence of $\mathrm{NaAlO}_{2}$ as compared to reactions in $\mathrm{SnO}_{2} / \mathrm{H}_{2}$ or $\mathrm{H}_{2} /$ tetralin. The oil/asphaltene ratio obtained in the $\mathrm{CO} / \mathrm{H}_{2} \mathrm{O}$ reaction is alout twice that for the latter reactions. The oil fraction is found to 
be rich in phenolic compounds. Ross et al. ${ }^{36}$ found that the chemical composition of the benzene soluble fraction obtained from the reaction of Illinois $\mathrm{No} .6 \mathrm{coal}$. with $\mathrm{CO} / \mathrm{H}_{2} \mathrm{O} / \mathrm{KOH}$ at $400^{\circ} \mathrm{C}$ was similar to that obtained from tetralin/ $\mathrm{H}_{2}$ at the same temperature.

\section{d. Removal of Heteroatoms}

The selective removal of hetero-atoms from the coal structure when coal is treated with $\mathrm{CO} / \mathrm{H}_{2} \mathrm{O}$ mixtures have been reported. Ross et al. ${ }^{35}$ reported that more than half of the oxygen in coal is removed as $\mathrm{CO}, \mathrm{CO}_{2}$ and water by heating coal with $\mathrm{CO} / \mathrm{H}_{2} \mathrm{O}$ at $400^{\circ} \mathrm{C}$. Stenberg et al. ${ }^{38}$ reacted coal with $\mathrm{H}_{2} \mathrm{~S} / \mathrm{H}_{2} \mathrm{O}$ mixtures in the presence of a molybdenum catalyst and showed the effective and selective removal of sulfur from coal.

\subsection{Kinetics and Mechanism of Coal Conversion in $\mathrm{CO} / \mathrm{H}_{2} \mathrm{O}$} Systems

Ross et al. ${ }^{36}$ proposed a reaction scheme for coal liquefaction under $\mathrm{CO} / \mathrm{H}_{2} \mathrm{O}$. In this scheme, the route to coal conversion is seen as a paraliel to the wGS reaction. The WGS intermediate (probably a formate, see Fig.1) is the active reducing species and coal conversion is a consequence of the competition between bond cleavage/hydrogenation and retrograde reactions. The decomposition of the WGS intermediate has a positive isotope effect so that by adding $\mathrm{D}_{2} \mathrm{O}$ instead of $\mathrm{H}_{2} \mathrm{O}$, it was argued that the relative concentration of WGS intermediate was increased, thereby givins; rise to an overall improvement in conversion.

However, recent work by Stray and Jackson ${ }^{39}$ showed that the isotope effect disappeared when the coal was washed with dilute acid to remove the soluble mineral and inorganic matter. It was suggested that the isotope effect was a consequence of an interaction between the gas (hydrogen or deuterium) and the mineral and inorganic 
phases.

Although the precise mechanism by which coal conversion takes place is still unclear, Jackson et al. ${ }^{40.41}$ have shown that the kinetics of the coal conversion process relative to that of the wGS reaction is critical. They have demonstrated that the coal fragmentation process has to be compatible with the WGS reaction in order to obtain good conversion yields. Stenberg et al. ${ }^{42}$ have also demonstrated similar concepts by 'slowing' the radical fragmentation process via a temperature programming technique to enhance the efficiency of the hydrogen donating media (eg $\mathrm{H}_{2} \mathrm{~S} / \mathrm{H}_{2} \mathrm{O}$ with $\mathrm{CO}$ or $\mathrm{H}_{2}$ in the presence of pyrrhotite).

\subsection{Cross-linking Reactions and Impact of Oxygen Functional Groups in the coal structure}

In most proposed reaction schemes for improving liquefaction yields the focus is on enhancing the bond breaking reactions to overwhelm the retrograde reactions. It has been pointed out that these retrograde reactions are often encountered well before the reaction temperature is reached and could seriously affect the performance of coal during processing. Solomon et al. ${ }^{43}$ identified at least two distinct cross-linking events when coals were heated; one at Low temperature prior to bridge breaking reactions (depolymerization) exhibited by low-rank coals, and one at moderate temperatures subsequent to the initial bridge breaking reactions for high rank coals. For lignites, cross-linking begins at $200^{\circ} \mathrm{C} .{ }^{43}$ This is perhaps consistent with stage heating studies which indicated that a lower first stage pretreatment temperature is required for low-rank coals than high rank coals ${ }^{44,45}$ to minimize the potential for retrogressive reactions. Numerous pyrolysis, combustion and gasification studies have shown the impact of oxygen functional groups in coals on crosslinking and its influence on the tar yield, tar molecular weight distribution, char's surface area, fluidity, reactivity, etc. In liquefaction, cross-linking 
influences the short contact time yields and the distribution of preasphaltenes, asphaltenes and oils (see Ref. 43). It is apparent that controlling or minimizing these low-temperature cross-linking reactions is a key factor to obtaining high product yields and successful coal processing.

Recently Solomon et al. ${ }^{43}$ systematically studied the variation in cross-linking in coal with rank, temperature, heating rate and pretreatment. They and others ${ }^{46}$ have observed that low-temperature cross-linking associated with low-rank coals appeared to correlate with the evolution of $\mathrm{CO}_{2}$ and there was a good correlation between loss of carboxyl groups and evolution of $\mathrm{CO}_{2}$. Char solvent swelling and gas evolution studies have confirmed that lowtemperature cross-linking occurs simultaneously with $\mathrm{CO}_{2}$ and $\mathrm{H}_{2} \mathrm{O}$ evolution. Moderate-temperature cross-linking appeared to correlate best with methane formation.

Recent research has shown that low-temperature cross-linking can be significantly reduced by methylation, ${ }^{447}$ demineralization, ${ }^{48}$ by catalytic reactions, ${ }^{49}$ by the presence of a solvent, or by the presence of hydrogen.50 For example, Baldwin et al. " have shown that mild o-alkylation of a subbituminous coal can have a positive effect on the suppression of cross-linking reactions leading to an improvement in conversion yields. These effects were observed to be most pronounced at lower reaction temperatures. Although methylation has a significant impact on reducing cross-linking and subsequently improvement in conversion yields in both pyrolysis and liquefaction studies, alkylation technique requiring exotic chemicals (eg. Friedel-Crafts' reagent) is not practical in commercial operation. To induce mild alkylation, the use of alcohol in combination with a catalyst may be a more practical alternative. It has been shown that alcohols can alkylate and hydrogenate coal at moderate to high temperature.51,52 In coal liquefaction, the introduction of alkyl groups into aromatic nuclei in the coal structure increased lignite liquefaction in alcohol. s? 


\subsection{Chemical Pretreatment of Coal}

For coals, in general, at temperature below $300^{\circ} \mathrm{C}$ no significant thermal degradation of the coal macromolecular structure occurs. Therefore, shifting conditions to the lower end of this temperature regime, i.e., $200-320^{\circ} \mathrm{C}$, should preclude complications that occur as a result of competing retrograde reactions at high reaction temperatures $\left(>400^{\circ} \mathrm{C}\right)$. In this regard, chemical pretreatment techniques wich have been used for coal structural studies and those that have been extended for use to solubilize coal at moderately low temperatures may find application in this area. Studies that generated interest in this area include those conducted with strong alkaline solutions. Fischer et al. ${ }^{53}$ showed that part of the coal can be rendered soluble by simply heating coal with $\mathrm{NaOH}$ and $\mathrm{KOH}$ at elevated temperatures. They showed that the alkali-soluble product increased with temperature from 2.5 weight $\frac{\circ}{\circ}$ at $250^{\circ} \mathrm{C}$ to 21 weight $\frac{\circ}{\circ}$ at $300^{\circ} \mathrm{C}$. In a study on the action of aqueous alkali on lignin they found that the methoxyl structure in lignin was stable at $200^{\circ} \mathrm{C}$ in a $2.8 \% \mathrm{NaOH}$ solution. However, hydrolysis of this structure was almost complete at $300^{\circ} \mathrm{C}$. In a similar study Kasehagen ${ }^{54}$ reacted a Pittsburgh seam coal with sodium hydroxide from aqueous $1 \mathrm{~N}$ up to $100 \% \mathrm{NaOH}$ over a temperature range from $250-400^{\circ} \mathrm{C}$. His results showed that the maximum yield of alkali-soluble products was obtained with a rather dilute alkaline solution $(1-5 \mathrm{~N})$ at temperatures of 325 and $350^{\circ} \mathrm{C}$. The relatively small yields of alkali degradation products and the large fraction of insoluble residue suggested minimal hydrolysis of $\mathrm{C}-\mathrm{O}$ linkages occurred under these conditions and may be a reflection upon the rank of the coal. However, exhaustive extraction of the residue with benzene in a soxhlet produced significant benzene-soluble material up to $27 \%$ of the carbon in the coal compared to ca. 6-8\% in the raw coal. This indicated that some deep seated change in the coal structure had occurred although the data did not allow any mechanistic conclusions to be made. 
Earlier work by Withrow and pewbs with $\mathrm{KOH}$ and the monomethyl ether of ethylene glycol showed that the combination of a non-aqueous solvent with an alkali was superior to aqueous alkali solution. Further, it is well known that alcohols are much better swelling agents than water. Brooks and Sternhel $1^{56}$ found that the treatment of brown and subbituminous coals with alcoholic alkali at about $190^{\circ} \mathrm{C}$ for about 12 nours followed by acidification produces materials which are almost entirely soluble in alcohol or pyridine. Analyses of the reaction products showed a marked increase in hydrrgen anc in some cases a decrease in oxygen. However, the content of reactive oxygen functional groups (primarily phenolic and carboxyl groups) remained virtually unchanged. They concluded from these results that the reaction is not one of simple hydrolysis since no new functional groups have appeared. Carier and siemons ${ }^{57}$ suggested that alkali digestion of low-rank coai at mild temperatures is a physico-chemical phenomenon. In this view, the $\mathrm{Na}^{+}$ion diffuses into the pore structure of the coal and ionexchanges with the hydrogen of the oxygen functional groups ( $\mathrm{COOH}$ and phenolic $\mathrm{OH}$ ) in the coal structure. An electrical double layer initially forms between closely orientated carboxylate and phenolate groups which ultimately leads to electrostatic repulsion which separates the coal into smaller fragments. The ion-exchange mechanism is dependert on the $\mathrm{pH}$ of the solution used; at pH 7-8, the carboxylic acid functions are expected to ion-exchange with $\mathrm{Na}^{+}$ ions and followed by less accessible phenolic functions at $\mathrm{pH}>8$.

others have investigated the reaction of coal with alcohol-alkali mixtures at much higher temperatures. Ross and Blessing ${ }^{58}$ reported that a 'beneficiated' Illinois No.6 coal (PSOC-26) was converted to a fuldy pyridine-soluble product with $\mathrm{H} / \mathrm{C}$ ratios from 0.88 to 1.13 (cf. $H / C=0.79$ for the coal) when treated with isopropyl alcohol in the presence of either the alkoxide or $\mathrm{KOH}$ at $335^{\circ} \mathrm{C}$ for $90 \mathrm{~min}$. A higher pyridine solubles yield was obtained by Makabe et al. ${ }^{59}$ for the reaction of Taiheiyo coal with either ethanol or methanol in the presence of $\mathrm{NaOH}$ and $\mathrm{KOH}$ at $350^{\circ} \mathrm{C}$. They reported a good 
correlation between the ethanol extract yield and hydrogen absorbed into the coal, which corresponded to the difference between hydrogen produced in the blank test and hydrogen from the reaction. In agreement with Makabe's work, Ross and Blessing:8 reported that the product yield and elemental analysis of the pyridine solubles derived from the alcohol-alkali run and were similar to that of a run with tetralin at $335^{\circ} \mathrm{C}$.

The mechanism for conversion under the alcohol-alkali system at high temperatures $\left(>300^{\circ} \mathrm{C}\right)$ includes a hydrogenation step, but other reactions such as hydrolysis have been suggested as being important. Ross and: Blessing suggested that the mechanism of conversion at $335^{\circ} \mathrm{C}$ involves an initial hydrogenation of anthracene-like structures in the coal followed by thermolysis of the dihydro-intermediate. ${ }^{58}$ on the othex hand, Makabe et al. ${ }^{59,60}$ suggested hydrolysis as the main reaction for low-rank coals, in which other linkages are split, followed by hydrogenation. The hydrogen in the hydrogenation came from the reaction of the alcohol with the alkali hydroxide.

\section{Summary}

It can be seen from the various preceding sections that there are a number of problem areas that needs to be addressed. In line with one of our pretreatment objectives the removal of heteroatoms (oxygen, sulfur) has been shown to be most effective with the supercritical extraction and COSTEAM liquefaction processes at high temperatures (at least $380^{\circ} \mathrm{C}$ and above) and yet these processes have limited application in our work for two reasons. Firstly, high temperature is not desirable since it is not our objective to liquefy the coal in the pretreatment stage and, secondly, uncontrolled deoxygenation may ultimately lead to undesirable cross-linking and condensation reactions as shown by pyrolysis and extraction studies and discussed in section 2.6. A low pretreatment temperature may minimize cross-linking and other 
retrogressive reactions but the products may be relatively oxygen rich. ${ }^{41}$ Further, reaction kinetics tend to become slower at low temperatures so that pretreatment time may become an important consideration in the overall processing conditions. Thus, any successful coal methodology may have to be a compromise between the factors governing the high/low temperature extremes.

\section{Experimental plan for Screening Operating Variables}

\subsection{Coal and Coal preparation}

Initial work was carried out with a sample of Wyodak coal (No. 91648) while awaiting the Black Thunder coal sample to be shipped from CONSOL. This allowed us a better 'feel' on the direction of the project. For experiments carried out with a wGS catalyst $\left(\mathrm{NaOH}, \mathrm{KOH}, \mathrm{NaAlO}_{2}\right)$ the water soluble salt was dispersed by slurrying the coal prior to reaction. The procedure for dispersing the catalyst is described elsewhere. ${ }^{61}$ Although studies have shown that coal oxidation, particularly for brown coal, is detrimental to overall conversion during liquelaction, it is not a critical factor in the $\mathrm{CO} / \mathrm{H}_{2} \mathrm{O}$ system. Jackson et al. ${ }^{62}$ have shown that the partial oxidation of a high volatile bituminous coal at $105^{\circ} \mathrm{C}$ leads to a significant increase in coal conversion with $\mathrm{CO} / \mathrm{H}_{2} \mathrm{O}$ over the unoxidized coal. b Others ${ }^{51,56,59}$ have shown that the level of dissolution of low-rank coals (high oxygen content) with strong alkaline solutions is significantly greater than that of high-rank coals. Thus, coal handling may not be as critical in the pretreatment stage compared to the hydrogenation stage. If anything, these findings seem to suggest that coal oxidation may even help to make the coal more amenable to the co pretreatment process.

- In a corresponding experiment, the same oxidized coal when reacted in a hydrogen atmosphere showed a detrimental effect. 


\subsection{Pretreatment Catalyst}

The "catalysts" chosen for this study are well. known wGS and liquefaction promoters. They are not classical catalysts by definition and are therefore consumed or transformed to a different phase during the reaction. Thus, it is expected that a higher concentration of these promoters would be needed to sustain the reaction as compared to a classical catalyst. However, this is not expected to cause any major problem in subsequent processing of the pretreated coal as most of the bicarbonates and carbonate salts is expected to be saturated in the aqueous phase. Further, in theory, the inorganics should be separated efficient.ly from the pretreated coal during the oil agglomeration stage.

\subsection{Ractor Capacity: Micro-Reactors and Stirred Autoclaves}

Initial screening of reaction variables would be carried out with micro-reactors utilizing 2-3 gram coal samples to facilitate rapid identification of optimum reaction conditions. Subsequently, this would be scaled-up to generate samples of up to $100 \mathrm{~g}$ in a 1 -liter stirred autoclave as required.

\section{4 Temperature}

The temperature range selected for this particular study is ca. $200-320^{\circ} \mathrm{C}$. It is not the objective of the pretreatment process to liquefy the coal; however, to provide a complete picture, selected high temperature reactions are inevitable.

\subsection{Reducing gas}

The effect of changing the co/Ho molar ratio in the reaction system will be investigated since the wGS reaction runs parallel to the hydrogenation process. Investigations with synthesis gas will also be considered in view of its commercial application.

\section{6 water Concentration and Co-Solvent}

Using water in the pretreatment process can be done at relatively 
low pressures. The possibility of utilizing alcohol (eg. methanol) as a co-solvent will be examined. Alcohols have been used effectively as a supercritical fluid for extraction and liquefaction. ${ }^{58}$ Its ability to alkylate and hydrogenate coal has been documented. ${ }^{31,58,59,60,63}$ The latter reaction may be useful in complementing the WGS reaction at low pretreatment temperatures. Eurthermore, alcohols have been used as swelling agents in extraction studies and are also considered effective supercritical fluids for the removal of sulphur from coal. ${ }^{64}$

\subsection{Pretreatment Time}

The pretreatment time required to produce any meaningful results is anticipated to vary with the pretreatment temperature. At higher temperatures the kinetic process tends to proceed more rapidly than at a lower temperature. Initial work will be carried out for an hour to gauge the effect of the pretreatment process and to provide a baseline case for subsequent comparison at shorter pretreatment times.

\subsection{Organic Solvent Used in First Stage Hydroliquefaction}

It is possible that the effect of pretreatment may not be conspicuous due to masking effects by other factors such as utjlizing a high reaction temperature in the first stage liquefaction, prolonged reaction time, good hydrogenating solvent, etc. For example, it has been shown ${ }^{45,65}$ that the beneficial effect of coal pretreatment became clearer when a poor H-donor solvent was used in place of a good hydrogenating solvent or when only molecular hydrogen was present. In the ACLCP, a resid from the wilsonville pilot plant will be used as a vehicle solvent in the hydrogenation stage. Results from experiments with this residual solvent will be compared with other solvents (eg.tetralin or dihydroanthracene).

\subsection{Product Handling}

Graff and Brandes have shown that the pyrolysis and extraction 
yields from steam treated samples falls to the level for untreated coal when exposed to air.' In this study product workup and handling of the pretreated coal sample will be carried out under an inert atmosphere in a glove box and the results compared to samples which have been deliberately exposed to air.

\subsection{Product Characterization and Analysis}

select analyses on the pretreated coal derived from various reaction conditions will be performed using different techniques (elemental analysis, Fourier Transform-Infrared Spectroscopy and ${ }^{13} \mathrm{C}$ NMR). The performance of the pretreatment procedure will be gauged by hydroliquefaction yields followed by analysis of the products when applicable using a micro-distillation apparatus and the techniques described above.

\subsection{Optical Light Microscopy}

This work will be a collaborative effort with Dr. Bob Rathbone. Samples will be analyzed to ascertain changes in coal structure, particularly changes pertaining to oxygen functional groups and in conjunction with other criteria stated above, to assist in determining the direction of the project.

\section{TASK 2.3.1 Iron-Based, Dispersed Hydroliquefaction Catalysts}

Hydroliquefaction work during this quarter focused on ultra-fine particle (UFP) iron carbides. Both $\mathrm{E}_{3} \mathrm{C}$ and $\mathrm{Fe}_{7} \mathrm{C}_{3}$ phases, which were produced by laser pyrolysis at CAER, ${ }^{66,67,68}$ were tested as coal liquefaction catalyst precursors in 15-minute, vertically-shaken microautoclave experiments. Under the conditions that were used in the tests the data showed little activity for the $\mathrm{Fe}_{3} \mathrm{C}$ phase either alone or with added sulfur. However, a moderate level of activity was observed for the $\mathrm{Fe}_{7} \mathrm{C}_{3}$ phase. Comparative runs were made with the molecularly dispersed molybdenum and iron naphthenates which gave results similar to the $\mathrm{Fe}_{3} \mathrm{C}_{7}$ phase at mid-range liquefaction 
temperatures, although the effectiveness of the dispersed molybdenum compound was much better at higher temperature $\left(440^{\circ} \mathrm{C}\right)$.

\section{Experimental Methods}

A sub-200 mesh subbituminous wyodak coal was used in the experiments, and was dried prior to the reactions. Three grams of coal were used with five grams of tetralin as the hydrogen donor solvent. The iron carbide catalyst precursor was added at 1 weight \% (total Fe as metal) of the coal, as loaded to the $26 \mathrm{ml}$ tubing bomb reactor. When used, DMDS was added in an amount necessary for $120 \%$ stoichiometric conversion of the iron to pyrite.

Conversion experiments were run between $330^{\circ} \mathrm{C}$ and $440^{\circ} \mathrm{C}$. The reactors were charged to 800 psig with ultra-high purity hydrogen prior to heating. Reaction time commenced upon immersing the reactors in a heated sand bath, and ended at removal. Reactors were then gradually cooled in a cool, air fluidized sand bath to room temperature.

\section{Product Work-Up}

Soxhlet extractors were used to determine the yield of the liquefaction products, using benzene as the first extraction solvent. The benzene solubles were further classified into pentane insoluble (asphaltenes) and soluble (oil) fractions. The benzene insoluble materials were extracted again with pyridine; the soluble portion being labelled as preasphaltenes and pyridine insolubles as IOM. This solvent separation based classification procedure is shown in the figure below: 


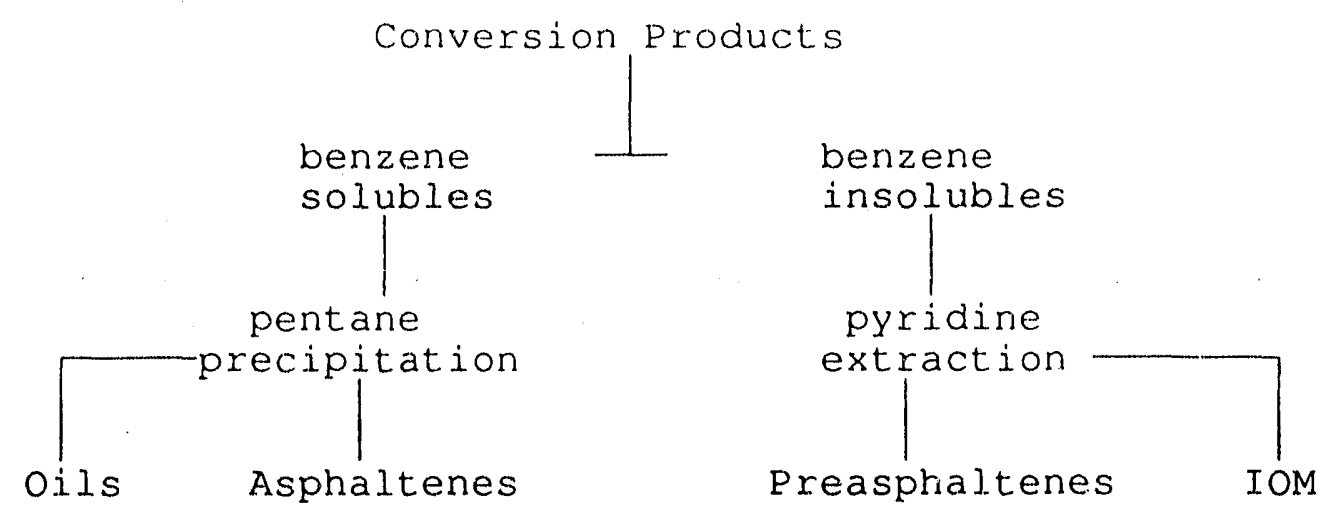

Coal liquefaction reaction product classification

Soxhlet extraction usually required 16 to 18 hours, but was continued as needed to reach a water white solvent color end-point. product samples were dried overnight at $80^{\circ} \mathrm{C}$ at $25^{\prime \prime} \mathrm{Hg}$. vacuum.

These weights were then used to calculate the percent yield of the respective product, dividing by the initial coal weight on a moisture, ash-free (maf) basis. Asphaltene and preasphaltene yields were calculated directly from sample weights. Total conversion was calculated as $100 \%$ minus the weight percent IOM remaining in the extraction thimble (reduced by the theoretical. weight of ash), on a maf coal basis. The final weight of IOM was also reduced by the theoretical weight of pyrrhotite (as $\mathrm{Fe}_{9} \mathrm{~S}$ ) that could be produced from the weight of iron added, as the stable sulfide form observed from Mössbauer studies of reaction products and as reported in the literature. ${ }^{69,70}$

Gas samples from the batch microautoclave experiments were analyzed for mole percentages of $\mathrm{H}_{2}, \mathrm{O}_{2}$, $\mathrm{CO}, \mathrm{CO}_{2}, \mathrm{~N}_{2}$, and $\mathrm{CH}_{4}-\mathrm{C}_{2} \mathrm{H}_{6}$ by gas chromatography. The quantity of each gas produced was calculated using the ideal gas law, the mole percent in the gas sample, and the post-reaction vessel temperature and pressure. 
Oil and water produced in the reaction were calculated by the difference between total conversion and the individual component conversions calculated above, and are lumped together here as "Oil".

A "blank" experiment, following the solvent extraction procedure on unconverted coal, gave the following results (weight o moisture, ash free coall:

BLANK EXTRACTION

\begin{tabular}{|c|c|}
\hline Pyridine conversion & \\
\hline Gas yield & 0.0 \\
\hline Oil yield & 0.4 \\
\hline Asphaltene yield & 0.4 \\
\hline Preasphaltene yield & 3.6 \\
\hline
\end{tabular}

Total

100.0

Notwithstanding this analysis, this report follows the convention that all numbers presented are absolute values of the converted component.

\section{Reagents Used}

The table below lists the reagents used in this work. 
REAGENTS USED IN TASK 2.3.1, SECOND QUARTERLY REPORT

\begin{tabular}{|l|l|l|}
\hline \multicolumn{1}{|c|}{ Reagent } & \multicolumn{1}{|c|}{ Grade } & \multicolumn{1}{|c|}{ Source } \\
\hline Benzene & OmniSolv & EM Science \\
\hline Pentane & $\begin{array}{l}\text { B\&J Brand High } \\
\text { Purity Solvent }\end{array}$ & Baxter S/P \\
\hline Pyridine & $\begin{array}{l}\text { B\&J Brand High } \\
\text { Purity Solvent }\end{array}$ & Baxter S/P \\
\hline THF & $\begin{array}{l}\text { B\&J Brand High } \\
\text { Purity Solvent }\end{array}$ & Baxter S/P \\
\hline DMDS & practical (>99\%) & Eluka AG \\
\hline Tetralin & $99 \%$ & Aldrich Chemical Co. \\
\hline $\begin{array}{l}\text { Molybdenum } \\
\text { Naphthenate }\end{array}$ & $6.05 \%$ molybdenum & $\begin{array}{l}\text { K\&K Laboratories Div. } \\
\text { ICN Biomedicals, Inc. }\end{array}$ \\
\hline $\begin{array}{l}\text { Ferric } \\
\text { Naphthenate }\end{array}$ & $\begin{array}{l}6.1 \% \text { iron } \\
\text { Hydrogen }\end{array}$ & K\&K Laboratories \\
\hline
\end{tabular}

\section{Experimental Error}

Coal liquefaction experiments at two different temperatures without either catalyst or added sulfur give an estimate of the pure experimental error, shown as the standard deviation, $\sigma$, in the table below for each fraction separated in the product work-up. Five of the six experiments used in the calculations were conducted on different days. 


\section{EXPERIMENTAI STANDARD DEVIATIONS}

we

\begin{tabular}{lcccc} 
& \multicolumn{2}{c}{$367^{\circ} \mathrm{C}$} & \multicolumn{3}{c}{$391^{\circ} \mathrm{C}$} \\
Pyxidine Conversion & $39.1 \pm 1.1^{\circ}$ & $(2.7 \%)^{\circ}$ & $52.5 \pm 1.3$ & $(2.4 \%)$ \\
Gases Yield & $2.8 \pm 0.03$ & $(0.9 \%)$ & $2.8 \pm 0.07$ & $\left(2.5 \frac{\circ}{\circ}\right)$ \\
Oil Yield & $16.7 \pm 0.8$ & $(4.5 \%)$ & $24.0 \pm 1.8$ & $(7.6 \%)$ \\
Asphaltene Yield & $10.1 \pm 0.8$ & $(7.7 \%)$ & $15.6 \pm 2.4$ & $(15.2 \%)$ \\
Preasphaltene Yield & $9.4 \pm 0.5$ & $(5.7 \%)$ & $10.1 \pm 2.0$ & $(20.0 \%)$ \\
Preasphaltene + & & & & \\
Asphaltene Yld (PA\&A) $^{\mathrm{c}}$ & $19.6 \pm 1.0$ & $(5.1 \%)$ & $25.7 \pm 1.7$ & $(6.7 \%)$
\end{tabular}

a. Mean \pm standard deviation, $\sigma$, with 2 degrees of freedom.

b. Standard deviation as a percent of mean $(\sigma /$ mean-100).

c. A calculated result only.

As can be seen from the table, total pyridine conversion was among the most reproducible portion of the work-up (with yields \pm 1.1 and 1.3\%, respectively). Although small in absolute terms, the product: fractions precipitated earlier in the analysis showed more variability when calculated as a percent of the mean, particularly the asphaltene and preasphaltene cuts at $391^{\circ} \mathrm{C}$. However, when considered together as a total (the last line of the table), the PA\&A yield was more consistent.

\section{Results and Discussion}

Experiments using a variety of catalyst precursors confirmed that the coal liquefaction followed a typical subbituminous pathway when results were displayed on triangular coordinates. ${ }^{71}$ While beneficial to coal conversion, the iron carbide experiments also followed this same pathway.

$\mathrm{Fe}_{3} \mathrm{C}$

Data from coal liquefaction experiments using only coal and tetralin ("thermal"), and from experiments using coal, tetralin and 
DMDS were presented in the First Quarterjy Report. Here in Figure 2, the initial work on the UFP iron carbide Fe ${ }_{3} C$ phase is presented using the thermal data as a benchmark. First, experiments were conducted adding only the iron carbide, shown as open boxes in Figure 2, and then with sulfur added as DMDS, shown as the dark boxes. In both cases, the dense iron carbide showed little, if any, discernable effect.

It has been hypothesized that the carbide activity may be inhibiled by a passive oxide coating. ${ }^{72}$ By the end of the reactions, however, the carbides were converted to the active phase. Fifteen and 30 minute sulfiding studies with $\mathrm{Fe}_{3} \mathrm{C}$ sample \#64, tetralin and DMDS at $367^{\circ} \mathrm{C}$ reaction conditions, absent the coal, confirmed the carbide was converting to pyrrhotite within the 15 minute reaction time.

\section{$\underline{E}_{7} \underline{C}_{3}$}

Experiments were conducted using UFP iron carbide in the $\mathrm{Fe}_{7} \mathrm{C}_{3}$ phase as a catalyst precursor, with DMDS added for sulfur. Figure 3 shows the results of this work, with modest activity shown in the 360 to $440^{\circ} \mathrm{C}$ range. The solid lines on this set of graphs shows the thermal conversion results without any added precursors or sulfur.

\section{Moly Naphthenate and Iron Naphthenate}

As a touchstone comparison with molecularly dispersed precursors, three experiments were run with molybdenum naphthenate, and one with iron naphthenate. These results are displayed in Figure 4. Interestingly, the moly naphthenate showed activity comparable to the iron carbide at the mid-range temperatures, but was a much better oil producer at $440^{\circ} \mathrm{C}$. Elemental analysis of the moly naphthenate gave 6.5 wt\% Mo, compared to the 6.05 wt: vendor assay.

The iron naphthenate gave liquefaction results comparable to both the $\mathrm{Fe}_{7} \mathrm{C}_{3}$ and the moly naphthenate. 
Tabular data for all of the above experiments are presented in Table 1 .

In future work, three reasons will be investigated for the results observed:

1. The hydrogenation state of the solvent may be such that the impact of a good hydrogenation catalyst is not readily observed in a 15 minute experiment. Using the actual wilsonville resids in 60 minute runs should shed some light on this aspect.

2. The catalyst may not be properly dispersed.

3. The precursor may be converting to its active phase too late in the experiment to have a significant effect. This also will be addressed with longer run-times, as well as with presulfided catalyst runs and sulfiding kinetic studies on selected precursors.

\section{THE Conversion}

To show the effect of a different extraction solvent on conversion at $367^{\circ} \mathrm{C}$ (see thermal data from the Experimental Error section, above), THF was used following the procedure proposed for future use with the Black Thunder coal. The main differences in this work-up include extracting all components in the initial step, and then precipitating PA\&A together with pentane. This product workup compared fairly well with the standard benzene/pyridine procedure used here, as shown in the following table:

wt o maf coal.

\section{Bnz/Pyridine $\quad$ THE}

Total Conversion $39.1 \%$ $36.3 \%$

Gas yield

2.8

2.9

Oil yield

16.7

12.5

Asphaltenes yld

10.1

included below

Preasphaltenes yld

9.4 20.9

Insoluble organic material. Total

$\frac{60.9}{100.0 \%} \quad \frac{63.7}{100.0 \%}$




\section{Figure 2. Wyodak Liquefaction with Fe3C}
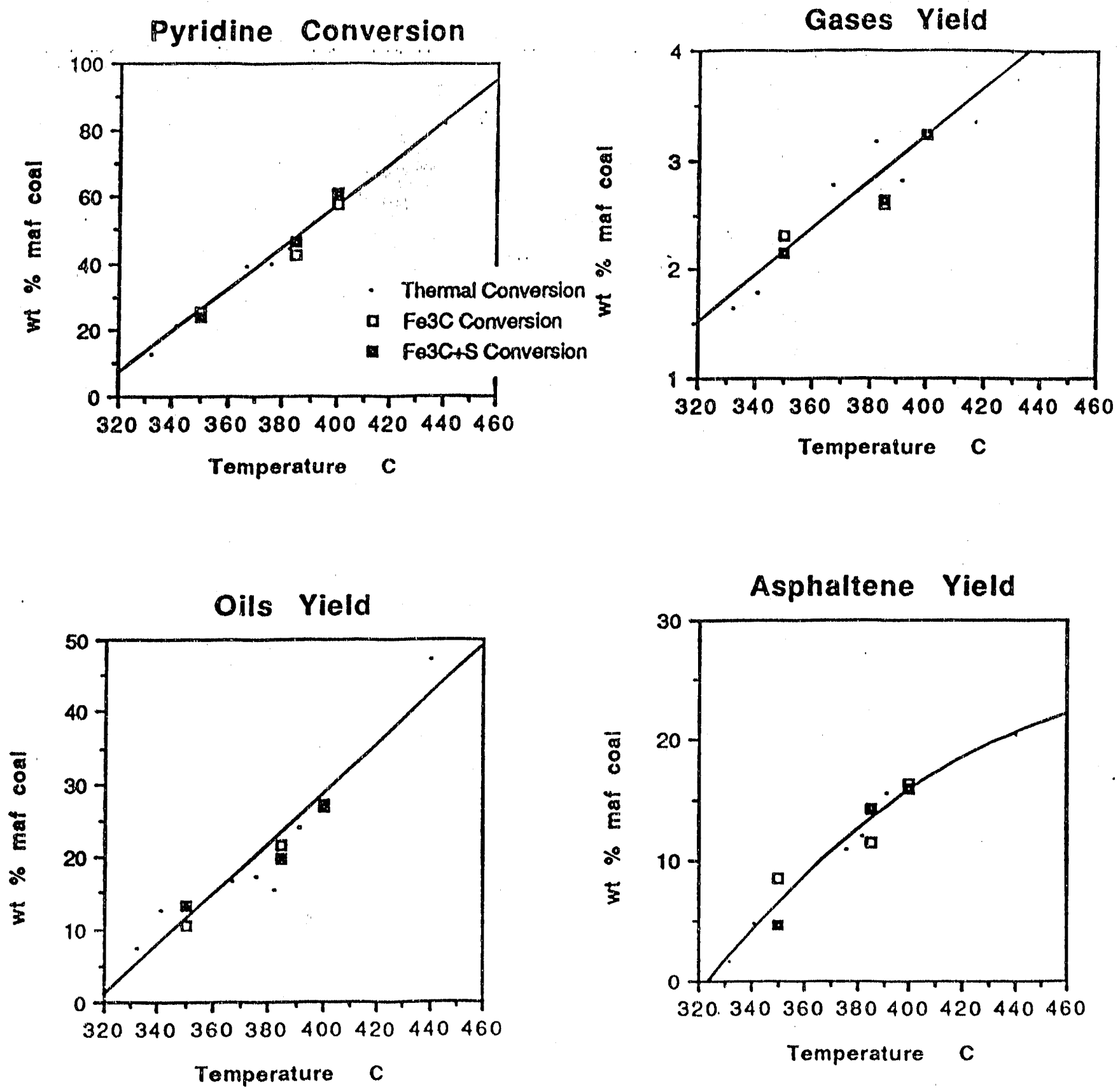

1 wt \% Fe/Coal; $2.4 \mathrm{~m} \mathrm{~S} / \mathrm{m} \mathrm{Fe}$ 15 minutes; 800 psig H2 (cold) Tetralin/Coal $=1.66: 1$ 


\section{Figure 3. Wyodak Liquefaction with Fe7C3 and Sulfur}
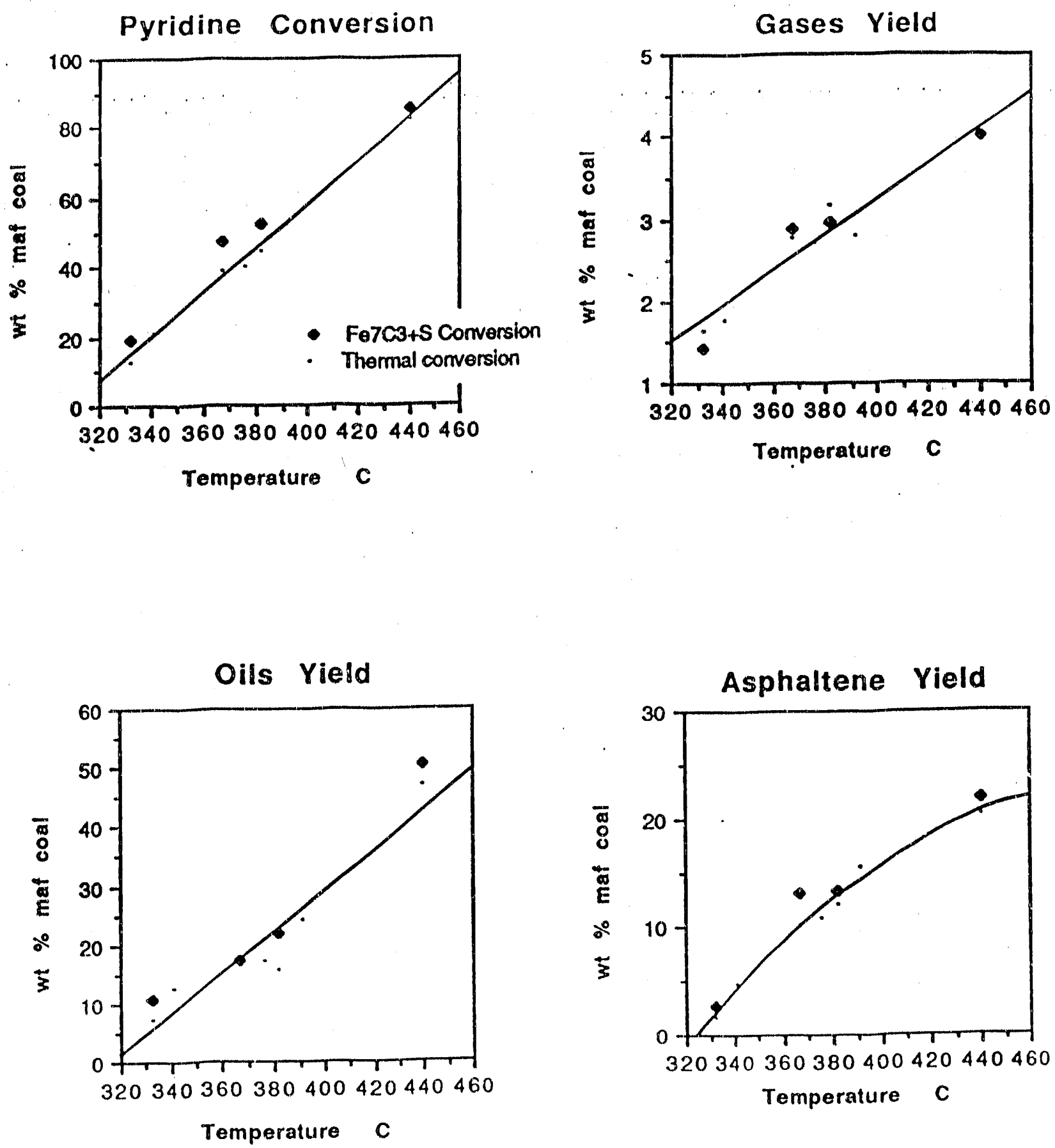

1 wl \% Fe/Coal; $2.4 \mathrm{~m} \mathrm{~S} / \mathrm{m} \mathrm{Fe}$

15 minutes; 800 psig $\mathrm{H}_{2}$ (cold)

Tetralin/Coal $=1.66: 1$ 


\section{Figure 4 Wyodak Liquefaction with Mo and Fe}
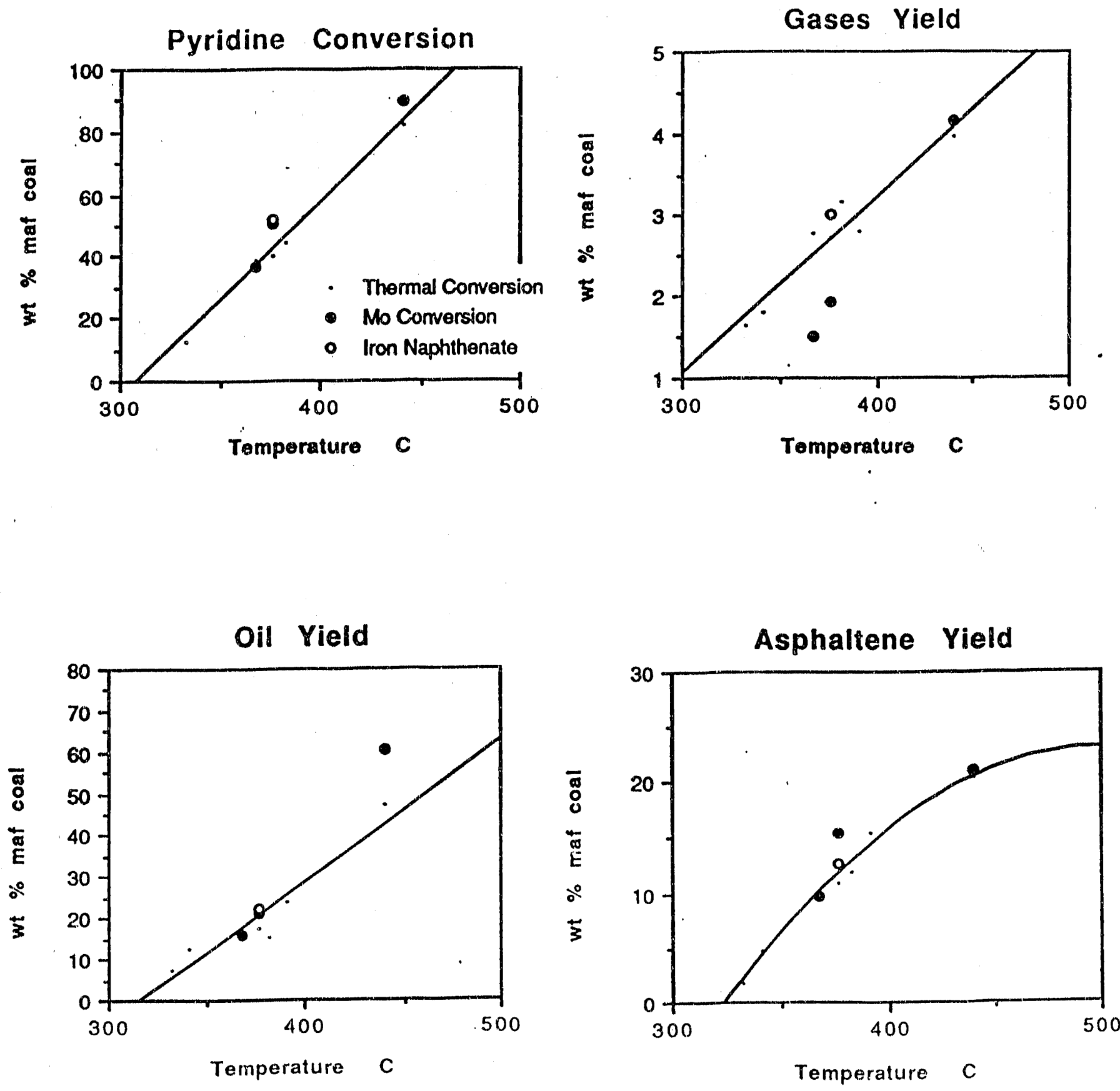

1 wt \% Metal/Coal; $2.4 \mathrm{~m} \mathrm{~S} / \mathrm{m}$ metal 15 minutes; 800 psig $\mathrm{H} 2$ (cold)

Tetralin/Coal $=1.66: 1$ 
TABLE 1

DATA FROM FIRST STAGE HYDROLIQUEFACTION EXPERIMENTS

TEMP TOTAL PYRIDINE GASES OIL \& ASPHALTENE PREASPH

${ }^{\circ} \mathrm{C}$. RUNS CONVERSION YIELD WATER YIELD YIELD

THERMAL EXPERIMENTS

$\begin{array}{rrrrrrr}332 & 1 & 12.7 & 1.6 & 7.3 & 1.7 & 2.1 \\ 341 & 1 & 21.2 & 1.8 & 12.7 & 4.8 & 1.8 \\ 367 & 3 & 39.1 & 2.8 & 16.7 & 10.1 & 9.4 \\ 376 & 2 & 40.0 & 2.7 & 17.3 & 10.9 & 9.0 \\ 382 & 1 & 44.6 & 3.2 & 15.6 & 12.0 & 13.9 \\ 391 & 3 & 52.5 & 2.8 & 24.0 & 15.6 & 10.1 \\ 440 & 1 & 82.1 & 4.0 & 47.1 & 20.4 & 10.6\end{array}$

DMD8, NO PRECURBOR

\begin{tabular}{|c|c|c|c|c|c|c|}
\hline $\begin{array}{l}332 \\
367 \\
376 \\
382\end{array}$ & $\begin{array}{l}2 \\
2 \\
1 \\
1\end{array}$ & $\begin{array}{l}15.0 \\
36.0 \\
48.8 \\
51.1\end{array}$ & $\begin{array}{l}1.6 \\
2.3 \\
2.6 \\
2.7\end{array}$ & $\begin{array}{r}9.6 \\
15.2 \\
24.8 \\
25.0\end{array}$ & $\begin{array}{r}2.8 \\
9.6 \\
12.7 \\
14.6\end{array}$ & $\begin{array}{l}1.0 \\
8.9 \\
8.7 \\
8.8\end{array}$ \\
\hline
\end{tabular}

$\mathrm{Fe}_{3} \mathrm{C}$, NO SULFUR

$350 \quad 1 \quad 25.1$

$385 \quad 2 \quad 42.6$

$400 \quad 1 \quad 57.8$

$2 \cdot 3$

2.6

10.4

3.2

21.6

27.2

8.6

11.6

3.8

16.3

6.8

$\mathrm{Fe}_{3} \mathrm{C}$ WITH DMDS

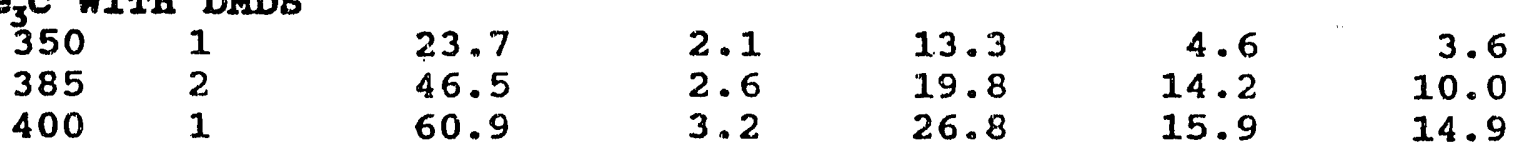

FefC $C_{3}$ WITH DMDS

$\begin{array}{rrrrrrr}332 & 1 & 19.0 & 1.4 & 10.6 & 2.7 & 4.2 \\ 367 & 2 & 46.9 & 2.9 & 17.3 & 13.1 & 13.7 \\ 382 & 1 & 52.1 & 3.0 & 21.9 & 13.4 & 13.9 \\ 440 & 2 & 85.5 & 4.0 & 50.3 & 21.8 & 9.4\end{array}$

MOLYBDENUM NAPHTHENATE

$\begin{array}{rrrrrrr}367 & 1 & 37.1 & 1.5 & 16.0 & 9.7 & 9.8 \\ 376 & 1 & 51.0 & 1.9 & 21.4 & 15.5 & 12.1 \\ 440 & 1 & 89.4 & 4.1 & 60.3 & 21.0 & 3.9 \\ & & & & & & \\ \text { ERRIC } & \text { NAPHTHENATE } & & & & & \\ 376 & 1 & 52.2 & 3.0 & 22.3 & 12.8 & 14.1\end{array}$

$5-4-92$ 
The THF extraction procedure shows lower overall conversion, yielding less oil, while the PA\&A fractions are about the same.

\section{TASK 2.3.3 Catalyst Studies at Sandia}

Two different types of supported catalysts were used to test activity for the combined water-gas shift hydrogenation of a synthetic donor solvent. The first catalyst was a hydrous titanium oxide (HTO) catalyst which had been exchanged with platinum, and the second was an alumina catalyst loaded with cobalt and molybdenum.

The platinum catalyst was synthesized as a candidate catalyst to increase the rate of the solvent hydrogenation reaction. This catalyst gave a $95 \%$ conversion for $\mathrm{co}$ (equilibrium conversion is $97 \%$ ) in the water-gas shift reaction at $275^{\circ} \mathrm{C}$ after it was calcined at $500^{\circ} \mathrm{C}$. Solvent hydrogenation using this catalyst was lower than that of previous catalyst tests (Pyrene hydrogenation was 698 for a NiMo HTO, and $58 \%$ for the Pt HTO at $275^{\circ} \mathrm{C}$ ). However, the platinum catalyst performed well at $300^{\circ} \mathrm{C}$, hydrogenating $80 \%$ of the pyrene in the feed.

The cobalt molybdenum catalyst also showed lower hydrogenation activity $\left(34 \%\right.$ pyrene hydrogenated at $\left.275^{\circ} \mathrm{C}\right)$. Conversion of $\mathrm{CO}$ was lower $\left(60 \%\right.$ at $\left.275^{\circ} \mathrm{C}\right)$ with the cobalt molybdenum catalyst, possibly due to the lack of an alkali. promoter.

These results show that the best catalysts tested to date, for the combined water-gas shift solvent hydrogenation, is a sulfided NiMo catalyst (see Oct-Dec 1991. Quarterly Report).

\section{Background}

Pretreatment work at Sandia consists of solvent hydrogenation using the water-gas shift reaction. The aim of the work is to reduce 
reaction temperature and pressure for donor solvent hydrogenation and to remove the requirement for purified hydrogen. The use of water and co mixtures involves two classes of coupled catalytic reactions:

Water-gas shift

$$
\mathrm{H}_{2} \mathrm{O}_{(g)}+\mathrm{CO}_{(g)} \neq \mathrm{H}_{2(g)}+\mathrm{CO}_{2(g)}
$$

Hydrogenation of donor species, for example:

$$
\text { Pyrene }+\mathrm{H}_{2(g)}-4,5 \text { Dihydropyrene }\left(\mathrm{H}_{2} \mathrm{Py}\right)
$$

Hydrogenation of the donor solvent species is illustrated here by the hydrogenation of pyrene, a donor solvent precursor. Equilibrium concentrations of hydrogen and $\mathrm{H}_{2} \mathrm{PY}$ are greatly increased at lower temperatures due to the greater $K_{p}$ for the above reactions. The ability to lower the coupled reaction temperature allows the total system pressure to be reduced and still achieve adequate solvent hydrogenation.

Solvent pretreatment using hydrogen from an in-situ water-gas shift reaction is very efficient at low temperatures. For this reason, a catalyst which is active at low temperatures $\left(<300^{\circ} \mathrm{C}\right)$ for both water-gas shift and solvent hydrogenation is very desirable. Catalyst testing at sandia to date, has involved hydrogenation of a synthetic solvent containing 9.5 wt $\frac{0}{6}$ aromatic compounds in hexadecane. Synthesis gas $\left(50 \% \mathrm{CO}, 50 \% \mathrm{H}_{2}\right)$ and steam are reacted with the solvent in a trickle-bed reactor to produce hydrogen, and hyorogenate the solvent in one step.

\section{Catalyst studies}

We have synthesized a platinum based hydrous titanium oxide catalyst for low temperature hydrogenation. The catalyst was 
prepared from a platinum ammonium nitrate salt which was ion exchanged onto sodium titanate. Platinum content of the catalyst precursor was $1.75 \%$ by weight. Results from thermogravimetric analyses showed that the platinum appeared to be reduced (to metal) at approximately $200^{\circ} \mathrm{C}$ in forming gas $\left(2 \frac{\circ}{\mathrm{H}_{2}}\right.$ in $\left.\mathrm{N}_{2}\right)$. These results indicated that the catalyst could be effectively reduced in the trickle-bed reactor at or below $250^{\circ} \mathrm{C}$.

After an initial air calcination at $200^{\circ} \mathrm{C}$ the catalyst was ground to a $-30+40$ mesh particle size, packed in the reactor and reduced in hydrogen for two hours at $250^{\circ} \mathrm{C}$. This catalyst showed marginal activity (see table 2) and it was suspected that residual nitrogen compounds from the synthesis were the cause. Elemental nitrogen analysis showed that $900 \mathrm{ppm}$ of nitrogen remained on the $\mathrm{pt}$ catalyst after the relatively mild $200^{\circ} \mathrm{C}$ pretreatment. As a result, a higher temperature $500^{\circ} \mathrm{C}$ calcining step was used to prepare a second catalyst. Residual nitrogen was determined to be less than $30 \mathrm{ppm}$ on this catalyst. Activity test results are given in Table 2 .

\section{Solvent Pretreatment}

Solvent pretreatment tests were run using the synthesized Pt HTO catalyst as well as a commercially available Como on alumina catalyst. All catalysts were packed in the trickle bed reactor after they were crushed and sieved to a $-30+40$ mesh particle size. Reactions were performed after suitable catalyst pretreatment. A $50 \% \mathrm{CO}-50 \% \mathrm{H}_{2}$ mixture was used with steam to hydrogenate the concurrently flowing synthetic solvent. Weight Hourly space velocity (WHSV) was $0.5 \mathrm{hr}^{-1}$ on an aromatic feed basis. Gas chromatography was used to evaluate co conversions and capillary gas chromatography was used to measure hydrogenation of the aromatic feed components. Results from these tests are shown in Table 2 . 


\section{Platinum Catalyst Results}

Two flow reaction experiments were carried out. Results from solvent hydrogenations and the water-gas shift co conversions for the first (calcined at $200^{\circ} \mathrm{C}$, reduced at $250^{\circ} \mathrm{C}$ ) and the second (calcined at $500^{\circ} \mathrm{C}$, reduced at $250^{\circ} \mathrm{C}$ ) are presented in table 3 .

Table $2 \mathrm{Pt}$ HTO catalyst (Total sustem Pressure=1400 psig)

\begin{tabular}{|c|c|c|c|c|c|}
\hline Calcining & Temperature & CO conv. & & Hydrog & nated \\
\hline Temp. $\left({ }^{\circ} \mathrm{C}\right)$ & $\left({ }^{\circ} \mathrm{C}\right)$ & & BHEN & FLUOR & PYRENE \\
\hline 200 & 275 & 27 & 0 & 0 & 0 \\
\hline 500 & $275($ day 1$)$ & 95 & 35 & 56 & 58 \\
\hline 500 & $275($ day 2$)$ * & 96 & 15 & 25 & 22 \\
\hline 500 & $300($ day 1$)$ & 95 & 68 & 97 & 80 \\
\hline
\end{tabular}

The Pt catalyst performed well as a water-gas shift catalyst and hydrogenated $80^{\circ}$ of the pyrene at $300^{\circ} \mathrm{C}$. The feed solvent contained $200 \mathrm{ppm}$ of sulfur which is a possible cause of the deactivation. The product showed that the feed sulfur was completely removed at $300^{\circ} \mathrm{C}$.

\section{Cobalt Molybdenum Catalyst Results}

The cobalt molybdenum catalyst supported on alumina has $5.75 \%$ Mo and $1.65 \%$ Co with a surface area of $300 \mathrm{~m}^{2} / \mathrm{g}$. Previous tests with a supported Como catalyst showed that carbon monoxide was converted to $>90 \%$ (the previous catalyst had a Mo content of $9.3 \%$ and a co content of $2.7 \frac{\text { of }}{2}$. 
After the catalyst was packed in the reactor it was presulfided for two hours at $390^{\circ} \mathrm{C}$ with $9 \% \mathrm{H}_{2} \mathrm{~S}$ in hydrogen. Results for solvent hydrogenation with the como catalyst are presented in Table 2 .

Table 3 Como catalyst (Total system Pressure $=1000$ psig).

\begin{tabular}{ccccc}
$\begin{array}{c}\text { Temperature } \\
\left({ }^{\circ} \mathrm{C}\right)\end{array}$ & \multicolumn{3}{c}{$\%$ conv } & Hydrogenated \\
275 & 60 & 21 & 38 & 34 \\
300 & 76 & 12 & 33 & 26
\end{tabular}

This catalyst had a relatively low CO conversion compared to previous catalysts. The lower activity for this catalyst could be due to the lack of an alkali promoter (potassium or cesium). Potassium analysis on this catalyst showed that it contained less than 100 ppm by weight.

\section{Conclusions}

Both the Pt HTO and the Co.10 catalyst showed less activity at $275^{\circ} \mathrm{C}$ for solvent hydrogenation using the combined water-gas shift/solvent hydrogenation reaction than previous tests with NiMo formulated catalysts (See Oct-Dec 1991 Quarterly Report). The Pt catalyst was very sensitive to sulfur and nitrogen contamination and the Como catalyst showed less activity for water-gas shift conversion possibly because it lacked an alkaline promoter such as potassium.

\section{Fiture Tests}

Euture solvent hydrogenation tests will investigate the silicasupported HTO thin-film catalysts which have been coated multiple times with nickel and molybdenum to increase metal loading. In addition, a test using a platinum catalyst will study sulfur tolerance at slightly higher temperatures. Solvent hydrogenation 
using the heavy distillate baseline solvent from wilsonville run 262 will be initiated.

\section{Laboratory support}

Under subtask 1.3 four samples were received from Consol on March 26, 1992. The samples included: Black Thunder Coal, Deashed Resid, Ashy Resid, and a Heavy Distillate. All samples were from the wilsonville Run 262 and were received in good condition.

\section{REFERENCES}

1. Graff, R. A., S. D. Brandes, Energy and Fuels 1987, 1, p84

2. Matturo, M. G. et at., Energy and Euels, 1990, 4, p 346.

3. Schlosberg, R. H. et al., Fuel, 1980, 59, p. 45.

4. Baldwin, R. M. et al., preprints, Am. Chem. Soc., Div. of Fuel Chem. 1990, 35 (1), p. 70.

5. van Bodegom et al., Fuel, 1984, 63, p. 346.

6. Del Bianco, A. et al., Euel 1984, 63, p. 346.

7.Ross, D. S. et al., Fuel, 1984, 63, 1206.

8. Towne, S. E., Y. Shah, G. D. Holder, G. V. Deshpande and D. C. Cronauer, Fuel, 1985, 64, p883.

9. Bienkowski, P. R., R. Naragan, R. A. Greenkorn, K. C. Chao, Ind. Eng. Chem., 1987, 26, 202.

10. Paulitis, M. E., et al., DOE Quarterly Report, DOE/E2282PC50799, July-Sept. 1983.

11. Tiffany, D. M., T. J. Houser, M. E. MCCarvilie and M. E. Houghton, Preprints, Am. Chem. Soc., Div. of Fuel Chem., 1984, $29(5)$, p. 56

12. Townsend, S. H., M. A. Abraham, G. L. Hoppert, M. T. Klein, and S. C. Paspek, Ind. Eng. Chem. Res., 1988, 27, p. 143. 
13. Modell, M., "Gasification and Liquefaction of Forest products in Supercritical Water,", AIChE 89 th National Meeting, Portland, Oregon, Aug. 1980.

14. Deshpande, G.V., G. D. Holder, A. A. Bishop, J. Gopal and I. Wender, Euel, 1984,63, p.956

15. Bartion, P., Ind. Eng. Chem., Proc. Des. Devi, 1983, 22, p. 259.

16. Swanson, M. L., E. S. Olson, J. W. Diehl and S. A. Farnum, Preprints, Am. Chem Soc., Div. of Fuel Chem.,1986, 31(4), p.43.

17. Brandes, S. D., R. A. Graff, M. L. Gorbaty, and M. Siskin, Energy and Euels 1991, 3, p. 494.

18. Mapstone, J. O., Energy and Fuels, 1991, 5, p. 695.

19. Khan, M. R., W, Y, Chen, and E. Suuberg, Energy and Euels 1989,3, p. 223.

20. Ross, D. S., and A. Hirschon, Preprints, Am. Chem. Soc. Div. Euel Chem. 1990, 35 (1), p. 37.

21. Hoering, T. C., Organic Geochemistry, 1984, 5, p. 695.

22. Rozgony, T. G. et al., in Proceedings of tire $2 \mathrm{nd}$

International Conference on Processing and Utilization of High

Sulfur Coals, $Y$. Chugh, R. Caudle, C. Muchmore and A. Sinha, Eds. (Elsevier, New York, 1988).

23. Tse, D. S. et al., Preprints, Am. Chem Soc., Div. of Fuel Chem.,1991, 36(1), p. 23.

24. Serio, M. A. et a.., Preprints, Am. Chem Soc., Div. of Fuel Chem.,1990, 35 (1), p.61.

25. MCMillen, D. F. et al., Preprints, Am. Chem. Soc. Div. Euel Chem. 1985, 30(4), p. 414.

26. Trewhella, M. J. et al., Fuel,1988, 67, p.1135.

27. Siskin, M. et al., Energy and Fuels, 1990, 4, p.488

28. Ross, D. S. et al., Preprints, Am. Chem Soc., Div. of Fuel Chern., 1985, 30(3), p.94.

29. Appel1, H. R. et al., Preprints, Am. Chem Soc., Div. of Fuel Chem., 1968,12(3), p.220.

30. Appel], H. R., Energy, 1976, 1(4), p.24 
31. Jackson, W. R. et al., 1987 International Conference on Coal Science, Mastricht, Coal Science and Technology 11 (J.A.

Moulijn, K.A. Nater, H.A.G. Chermin. Eds.), p.45

32. Oelert, H.H et al., Euel, 1976, 55, p.39

33. Takemura, y. et al., Euel, 1983, 62, p.1133

34. Hodges, S. et al., Fuel, 1985, 64, p.1229

35. Ross D. S. et al., Energy and Fuels, 1987, 1, p.292

36. Ross, D. S., in "Coal Science," (M.I. Gorbarty, J.W. Larsen and I. Wender, Eds. ) Academic Press, Inc., New York, NY.

37. Lim, S.C., Ph.D Thesis, Monash University, 1990

38. Stenberg, V.I. et al., Preprints, Am. Chem. Soc., Div, of Euel Chem. 1984, 29(5), 63

39. Stray, G. and Jackson, W.R., Proc. 1986 Australian Coal

Science Conf., Newcastle. Australian Institute of Energy, p.245

40. Jackson, W.R. et al., Fuel 1992, 71(3), P. 343.

41. Hughes, C.P. et al., Accepted for publication in Fuel.

42. Stenberg, V.I. et al., Fuel, 1989, 68, p.133

43. Solomon, P. R. et al., Energy ard Fuels, 1990, 4, p.42

44. Derbyshire et al., preprints, Am. Chem. Soc., Div. of E'uel Chem., 1986, $31(4)$, p.308.

45. Derbyshire et al., preprints, Am. Chem. Soc., Div. of Fuel Chem., 1990, $35(1)$, p.51

46. Suuberg, E.M. et al., Fuel, 1985, 64, p.1669.

47. Solomon, P. R. et al., Preprints, Am. Chem. Soc., Div. of Fuel Chem. 1985, 30(4), p.346

48. Deshpande, G. V. et al, Preprints, Am. Chem. Soc., Div. of Fuel Chem. $1988,33(2)$, p. 310

49. Solomon, P. R. et al.,Preprints, Am. Chem. Soc., Div. of Fuel Chem. 1989, 34(3),803

50. Bockrath, B.C, et al., Energy and Fuels, 1987, 1, p.227

51. Kuznetsov et al., Fuel, 1990, 69, p.911 
52. Olson, E.S. et al.,preprints, Am. Chem. Soc., Div. of Euel Chem., 1986, 31(4), P.64

53. Fischer, F. et al., Ges. Abhandl. Kenntnis Kohle, 1920, 5,360

54. Kasehegen, L., Ind. Eng. Chem., 1937, 29, p.600

55. Withrow, J.R. et al., Fuel, 1931, 10, p.44

56. Brooks, J.D. et al., Fuel,1958, 37, p.124

57. Camier, R.J. et a.., Fuel, 1978, 57, p. 85

58. Ross, D.S. and Blessing, J.E., Euel, 1979, 58, p.438

59. Makabe, M., Hirano, Y. and Ouchi, K. 1978. Euel, 58, p.289

60. Makabe, M., Hirano, Y. and Ouchi, K. 1978. Euel, 58, p.289

61. Redlich, P.J. et al., Energy and Fuels, 1990,4, p.28

62. Jackson, W.R. et al., 1989 International Conference on Coal Science Tokyo. Proceedings Vol. 2, p.815

63. Garcia, R., Snape, C.E. and Moinelo, S.R. 1991 International Coal Conference Newcastle on Tyne p.178

64. Murdie, N., Hippo, E.J., Tao, W., Muchmore, C. and Kent, A., Fuel process. Technol., 1988, 18, p.119

65. Rindt, J.R., Hetland, M.D., Sauer, R.S., Sukalski, W.M. and Haug, L.W., Preprints, Am. Chem. Soc., Div, of Fuel Chem. ,198 vol? no?, p.83.

66. Haggerty, J.S., Cannon, W.R., 1981, in Laser-Induced Chemical Processes (Ed. JI Steinfeld), Plenum Press, New York, NY, USA.

67. Fiato, R.A. et al., 1987, US pat. 4,637,753.

68. Hager, G.T., Bi, X.X., Derbyshire, F.J., Eklund, P.C., Stencel, J.M., American Chemical Society, Div. of Fuel Chemistry, Preprints, 1991, 36(4) 1900-1908.

69. Djega-Mariadassou, G., Besson, M., et al., Euel Processing Technology, $12(1986), 143-153$.

70. Montano, P.A., and Granoff, B., Fuel, 59(1980), 214.

71. Keogh, R.A., and Davis, B.H., Preprints, Div. Fuel Chem., American Chemical Society, 1991, 36(2), 438-444. 
72. Derbyshire, F.J., and Hager, T., Presentation at the April, 1.992. ACS Meeting, San Francisco, CA. 

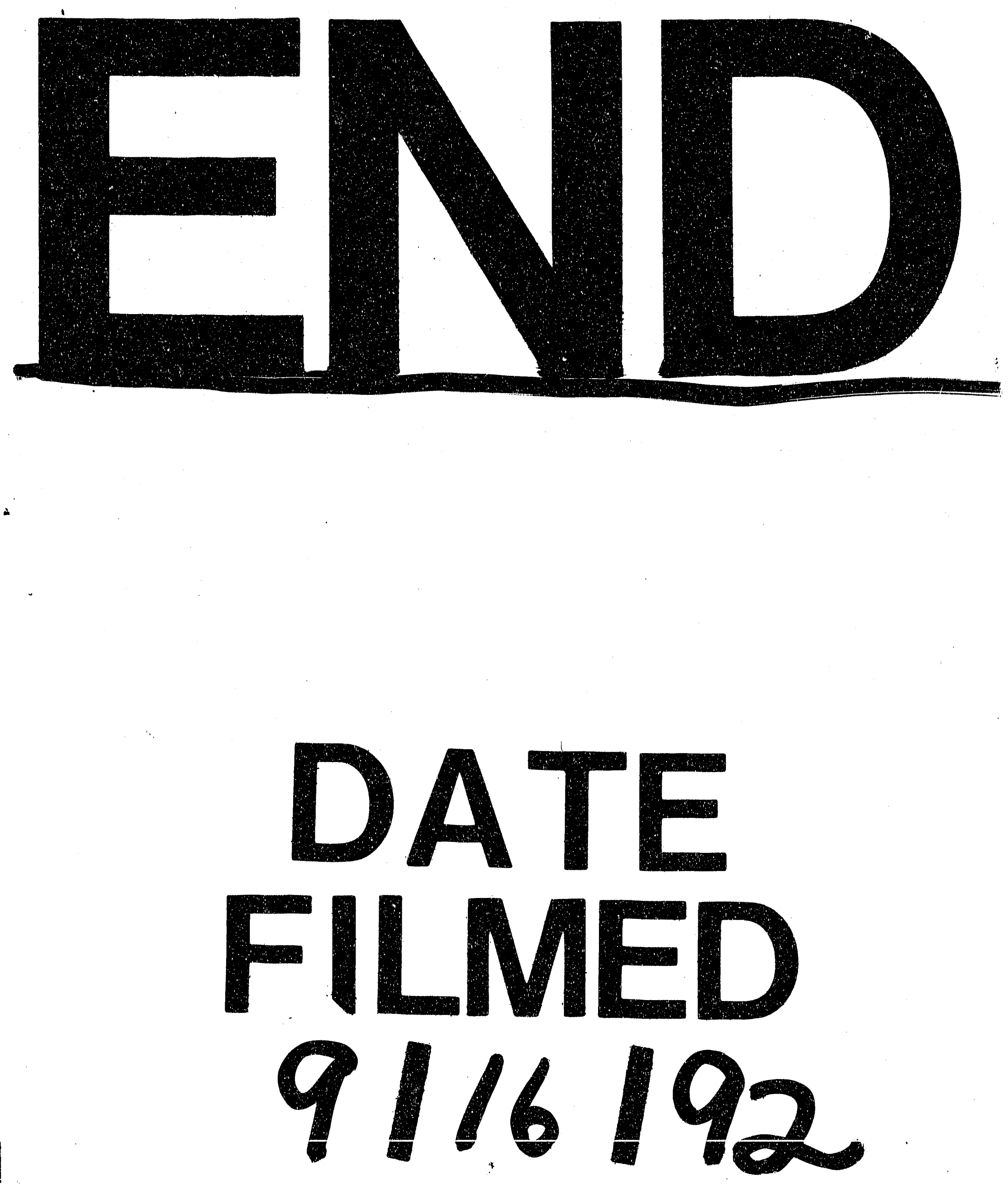
